\title{
ELECTROCHEMICAL KINETICS OF MOLTEN POTASSIUM THIOCYANATE ON PLATINUM. MECHANISMS OF ANODIC FILM FORMATION AND ITS CATHODIC DISSOLUTION*
}

\author{
A. J. Arvia, A. J. Calandra and M. E. Martins \\ Instituto Superior de Investigaciones, División Electroquímica, Facultad de Ciencias Exactas, \\ Universidad Nacional de La Plata, La Plata, Argentina
}

\begin{abstract}
Ahstract--The kinetics and mechanism of the anodic film formation and its cathodic dissolution on platinum, through electrolysis of molten potassium thiocyanate, were studied. Experiments were made at $190^{\circ} \mathrm{C}$ by applying both repetitive and single pulse linear sweep voltammetry. The kinetics of the anodic film formation is a film-growth-rate controlled process, whose mechanism comprises various steps: discharge, nucleus formation and growth. The discharge step is a fast process and the second step is postulated as rate-determining at low potential sweep rates; the corresponding Tafel slope is $R T / 2 F$. At higher potentials the larger reaction rates achieved make reaction sites undistinguishable. This fact reflects a change of reaction mechanism involving a different Tafel slope for the anodic film formation, which is twice the former slope. The corresponding $E / I$ curves are theoretically evaluated with parameters derived from the postulated mechanisms.
\end{abstract}

The dissolution process is not definitely established although the likely pathway is envisaged. The cathodic reaction is characterized by a Tafel slope of $R T / F$. The dissolution comprises a fast electron-transfer step followed by thiocyanate-ion formation; the latter appears as the slowest step.

Résumé-On a étudié la cinétique de la formation d'une pellicule anodique et la dissolution cathodique, a $190^{\circ} \mathrm{C}$, sur des électrodes de platine pendant l'électrolyse du sulfocyanure fondu, en appliquant la chronoampérometrie linéaire avec des balayages uniques et des balayages multiples.

La cinétique de la formation de la pellicule est controlée par la vitesse de croissance de la pellicule insoluble et le mécanisme comprend plusieurs étapes: décharge, formation et croissance du noyau. L'étape de décharge est un procèssus rapide et la deuxième étape est postulée comme l'étape de controle à des balayages de potentiel de faible vitesse. La pente de Tafel correspondante est $R T / 2 F$. $\tilde{A}$ des balayages de potentiel plus élevés la vitesse de la réaction augmente et la surface de l'électrode rend indiscernables les différents centres réactifs. Ce fait se manifeste par un change mert du mécanisme de réaction qui comporte une pente de Tafel $R T / F$. Sur la base des parametres déduits des mecanismes de réaction, on a calculé théoriquement les courbes $E / I$.

La réaction cathodique est caractérisé par une pente de Tafel $R T / F$. Le procèssus de dissolution $n^{\prime}$ est pas établi définivement mais un mécanisme de réaction probable est envisagé, qui comprend une étape de transfert d'électron rapide suivie par la formation d'ion sulfocyanure qui apparaît comme l'étape la plus lente.

Zusammenfassung-Es wurde die Kinetik und der Mechanismus der Bildung des anodischen Films und seiner kathodischen Lösung untersucht, wie er bei der Elektrolyse von geschmolzenem Kaliumthiocyanat an Platin auftritt. Die Untersuchungen wurden bei $190^{\circ} \mathrm{C}$ unter Anwendung sowohl der repetitiven als auch der Einzelpuls linearen Raster-Voltametrie durchgeführt. Die Kinetik der Bildung des anodischen Films ist ein die Wachstumsgeschwindigkeit des Films kontrollierender Prozess, dessen Mechanismus mehrere Schritte umfasst: Entladung, Keimbildung und Keimwachstum. Der Entladungsschritt verläuft schnell, während der zweite bei niederpotentialen Rastergeschwindigkeiten als geschwindigkeitsbestimmende Schritt angesehen wird. Die entsprechende Tafel-Neigung ist $R T / 2 F$. Bei höheren Spannungen werden durch die grösseren Reaktionsgeschwindigkeiten die Reaktionsorte ununterscheidbar. Diede Tatsache äussert sich in einer Ånderung der Reaktionsmechanismen, mit einer anderen Tafel-Neigung für die anodische Filmbildung, die doppelt so gross wie die erstere ist. Die entsprechenden $E / I$ Kurven werden theoretisch entwickelt mit Parametern, die aus den angenommenen Mechanismen abgeleitet wurden.

Der Lösungsprozess ist noch nicht eindeutig geklärt, obwohl sich ein möglicher Mechanismus abzeichnet. Die kathodische Reaktion ist durch eine Tafel-Neigung $R T / F$ charakterisiert. Die Lösung ist ein schnellverlaufender Elektronen-Transfer Prozess, gefolgt von der Bildung des Thiocyanat-Ions, wobei der letztere Schritt als der langsamste erscheint.

* Manuscript received 10 November 1970. 


\section{INTRODUCTION}

DURING recent years the electrochemical processes occurring on platinum through electrolysis of molten potassium thiocyanate have been the subject of various publications. ${ }^{1-4}$ One of the interesting reactions occurring at anodic potentials is the formation of an insoluble film of (SCN) $)_{x}$ which blocks the electrode surface, acting as a passivating film. The electrical characteristics of this film and conditions for its formation have been reported very recently. ${ }^{5}$ Accordingly the suitable experimental methods for a quantitative electrochemical study of the reactions were considered. Thus, once all attempts to obtain reliable data with steady-state techniques had failed, the possibility of using potential-sweep voltammetry appeared promising. The present report refers to $E / I$ results obtained under non-steady conditions which yield reliable kinetic parameters for a mechanistic interpretation of the film growth process at the electrode as well as suggesting the probable mechanism for its electrochemical dissolution. As far as these processes are concerned the reaction mechanisms earlier proposed for them are now definitely established.

\section{EXPERIMENTAL TECHNIQUE}

An electrolysis cell made of Pyrex glass of capacity $600 \mathrm{~cm}^{3}$ for the molten salt was used. Two platinum working electrodes were alternatively employed: one consisted of a platinum disk horizontally placed, having $0.071 \mathrm{~cm}^{2}$ area, which could be rotated at different speeds. The second was a platinum wire of $0.439 \mathrm{~cm}^{2}$, vertically placed in the melt. The counter-electrode was a large platinum sheet placed within a separate compartment, the electrical continuity between cell compartments being established by means of fritted glass disks. A third platinum electrode also placed into a separate compartment acted as an arbitrary reference electrode. The latter was mounted with the usual Luggin-Haber capillary tip arrangement. The electrolysis cell was placed into an air thermostat to run the experiments at $190 \pm 0.5^{\circ} \mathrm{C}$.

Molten potassium thiocyanate (Riedel de Häen and C. Erba) was employed as electrolyte. The salt was first dehydrated under vacuum, starting at room temperature and finishing when the salt was melted.

Repetitive linear-sweep voltammetry was applied as described in the literature. ${ }^{6}$ The repetitive cycles operated from $0 \cdot 3-22 \cdot 4 \mathrm{~V} / \mathrm{s}$, covering a potential amplitude range from $0-6.5 \mathrm{~V}$. The $E / I$ voltagrams were displayed on the screen of a Tektronix Type 502 A dual-beam oscilloscope.

Single-sweep voltammetry was also used. A circuitry was designed permitting change the potential sweep rate from $10^{-8}$ to $10^{3} \mathrm{~V} / \mathrm{s}$, in the direction of increasing as well as decreasing potential. The maximum and minimum potential limits were conveniently changed. Both the sweep rate and the potential limits were known to within 1 per cent. The $E / I$ voltagrams were recorded on a $X-Y$ Varian plotter. A further description of the circuitry for single-sweep voltammetry is given elsewhere. ${ }^{7}$

\section{RESULTS}

Experiments were made with electrodes either mechanically polished to a mirror surface or cathodically cleaned. The initial state of the electrode surface was quite important to achieve good reproducibility. The sweep voltammetry experiments were always performed with initially clean surfaces and particularly for single sweep runs, the first cleaning technique was preferred as it gave an apparently cleaner surface. 


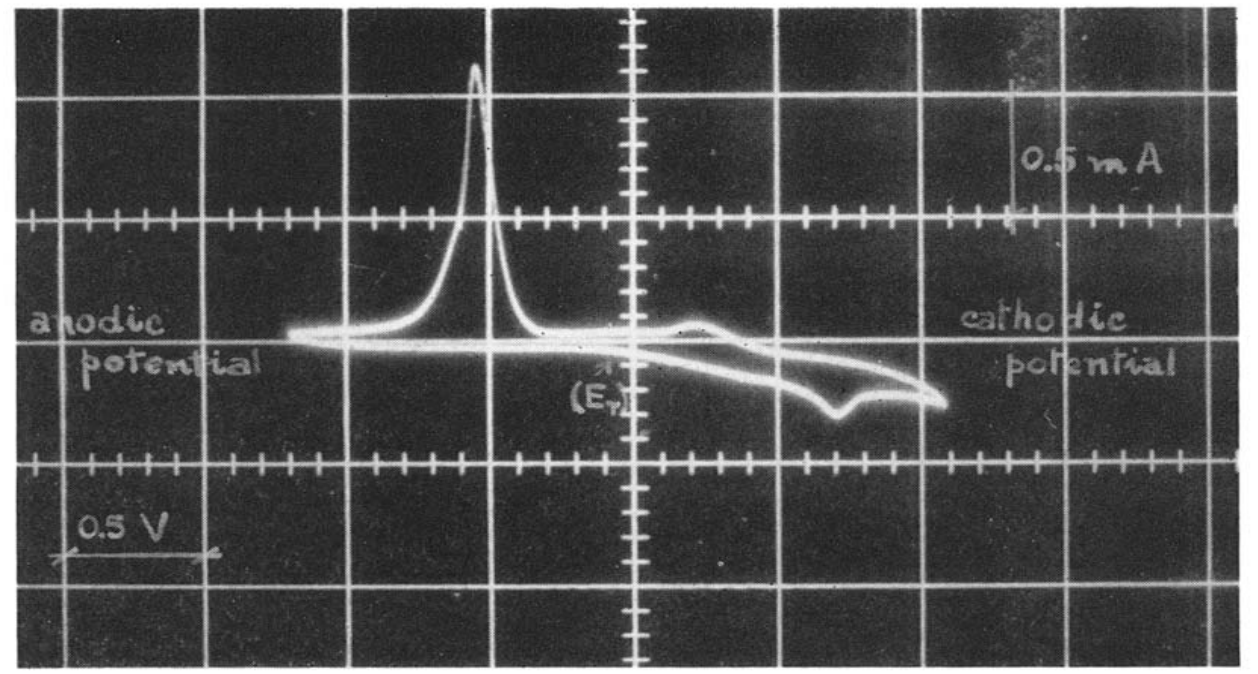

Fig. 1. Voltammetric $E / I$ curve obtained at $0 \cdot 324 \mathrm{~V} / \mathrm{s}$. Polished platinum disk electrude rotated at $186 \mathrm{rev} / \mathrm{min}$. $190^{\circ} \mathrm{C}$.

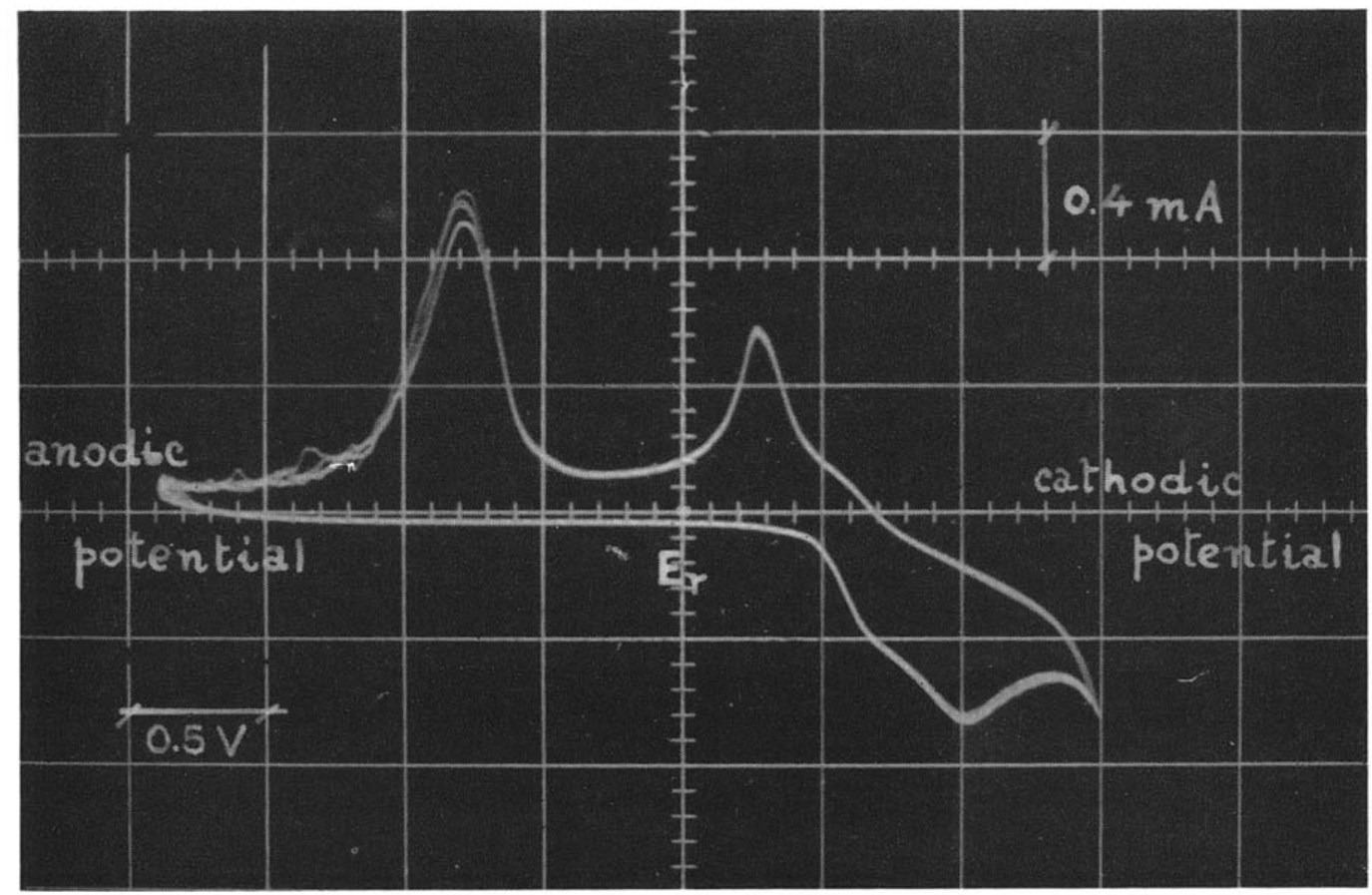

FIG. 3. Voltammetric $E / /$ curve obtained at $3.07 \mathrm{~V} / \mathrm{s}$. Stationary electrode. $190^{\circ} \mathrm{C}$. 


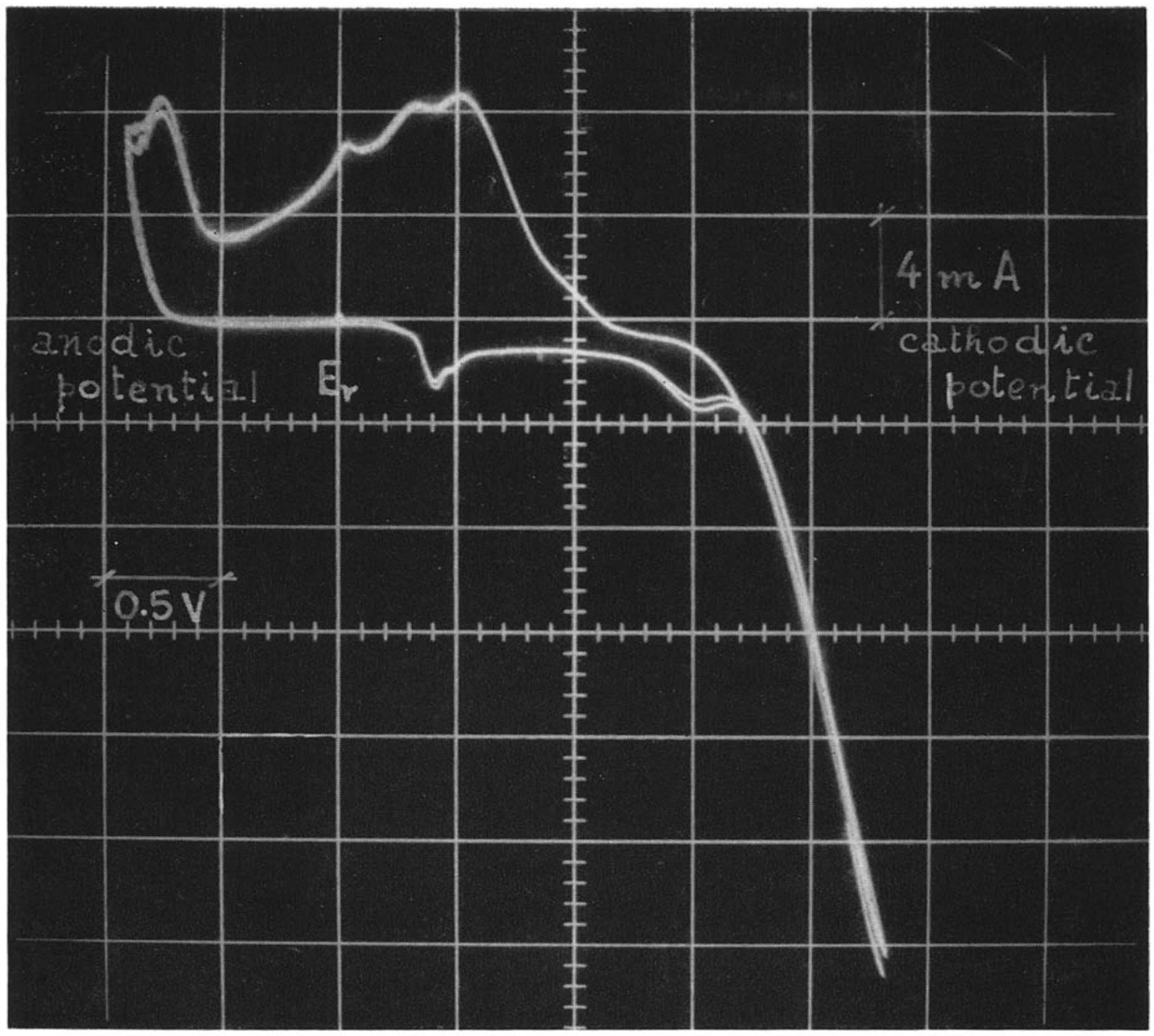

FIG. 4. Voltammetric E/I curve obtained at $0.464 \mathrm{~V} / \mathrm{s}$. Stationary electrode. $190^{\circ} \mathrm{C}$.

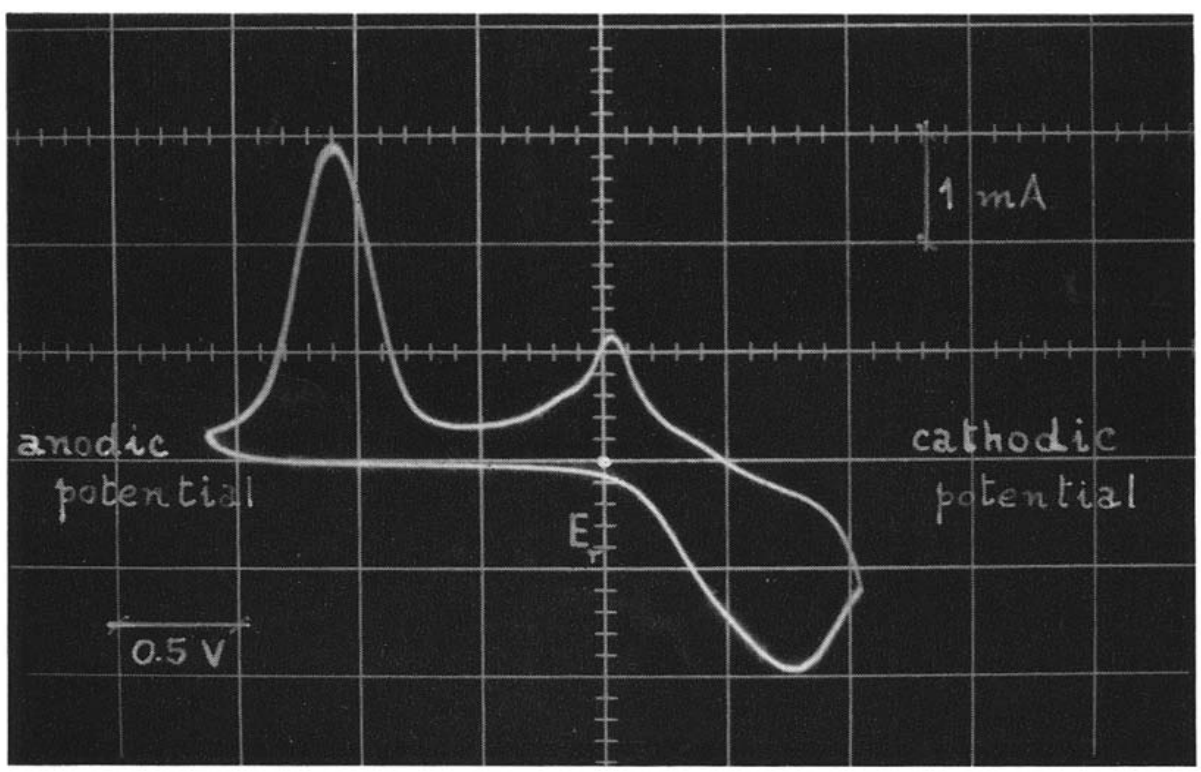

FIG. 5. Voltammetric $E / I$ curve obtained at $4.36 \mathrm{~V} / \mathrm{s}$. Electrode rotated at $632 \mathrm{rev} / \mathrm{min}$. $190^{\circ} \mathrm{C}$ 


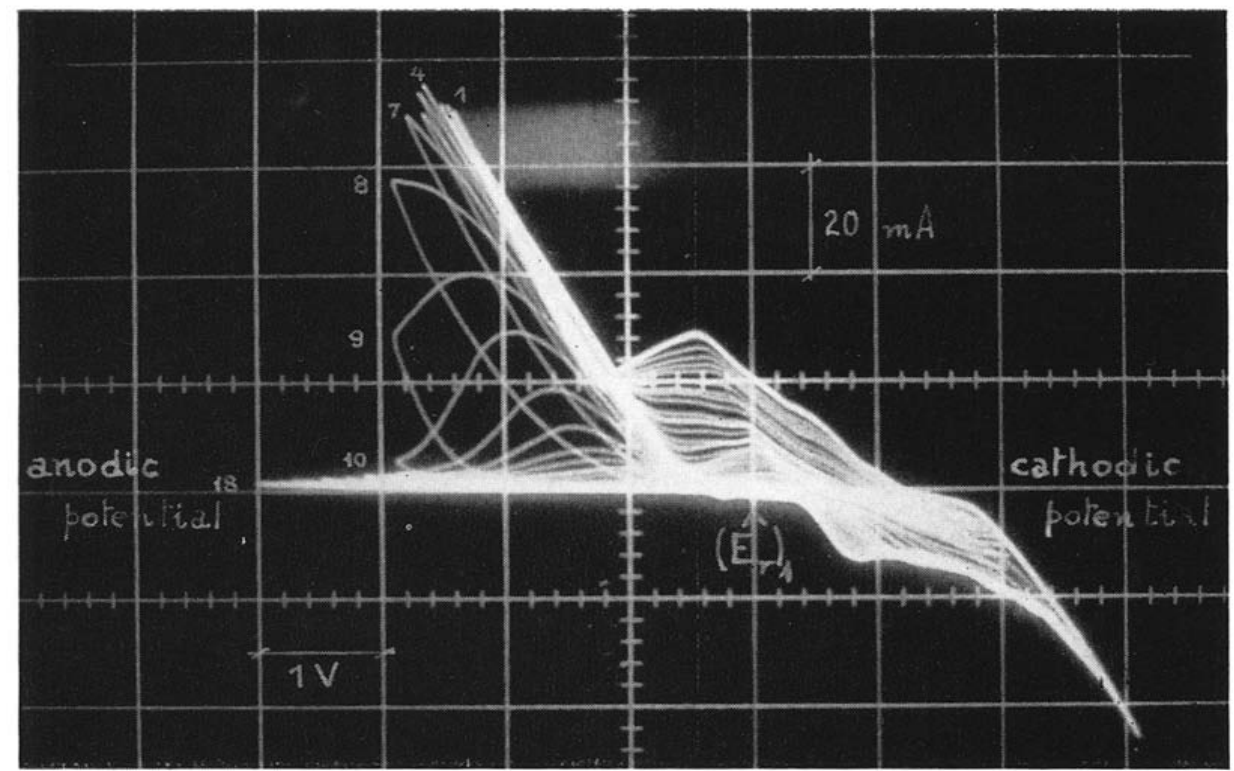

FIG. 6. Yoltammetric $E / I$ curve obtained by shifting the base potential continuously from the cathodic to the anodic region. Potential-sweep rate $22.4 \mathrm{~V} / \mathrm{s}$. $190^{\circ} \mathrm{C}$.

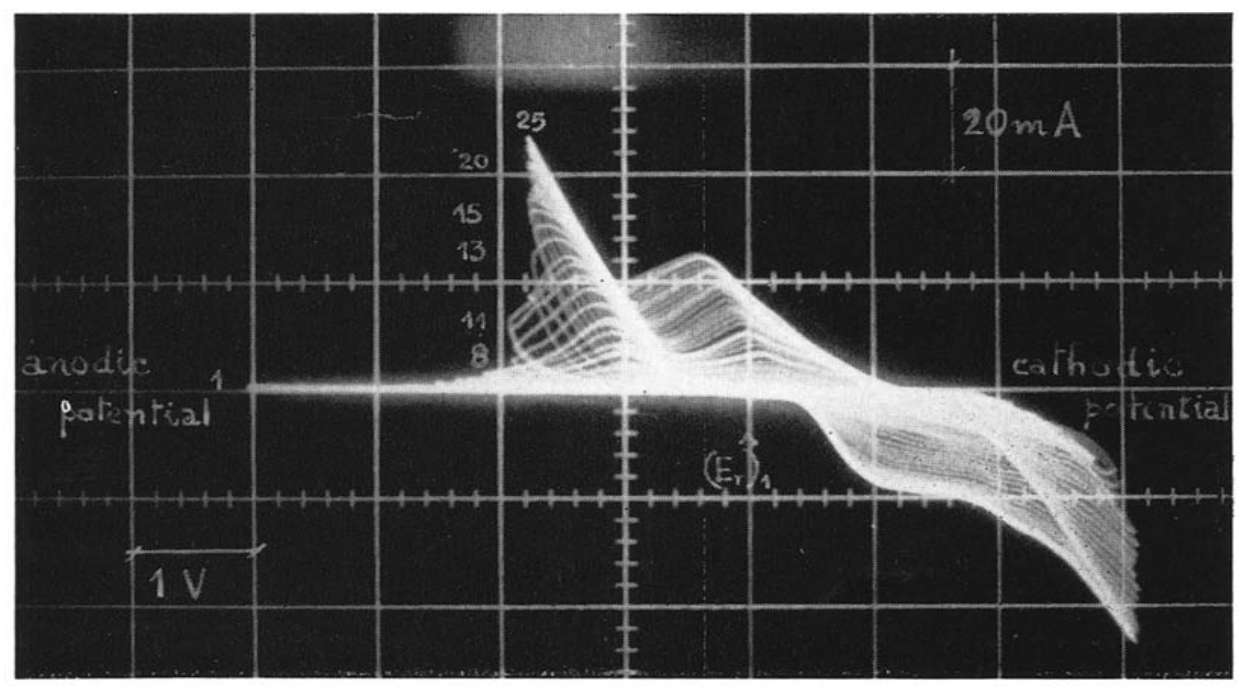

FIG. 7. Voltammetric $E / I$ curve obtained by shifting the base potential continuously from the anodic to the cathodic region. Potential-sweep rate $22 \cdot 4 \mathrm{~V} / \mathrm{s} .190^{\circ} \mathrm{C}$. 


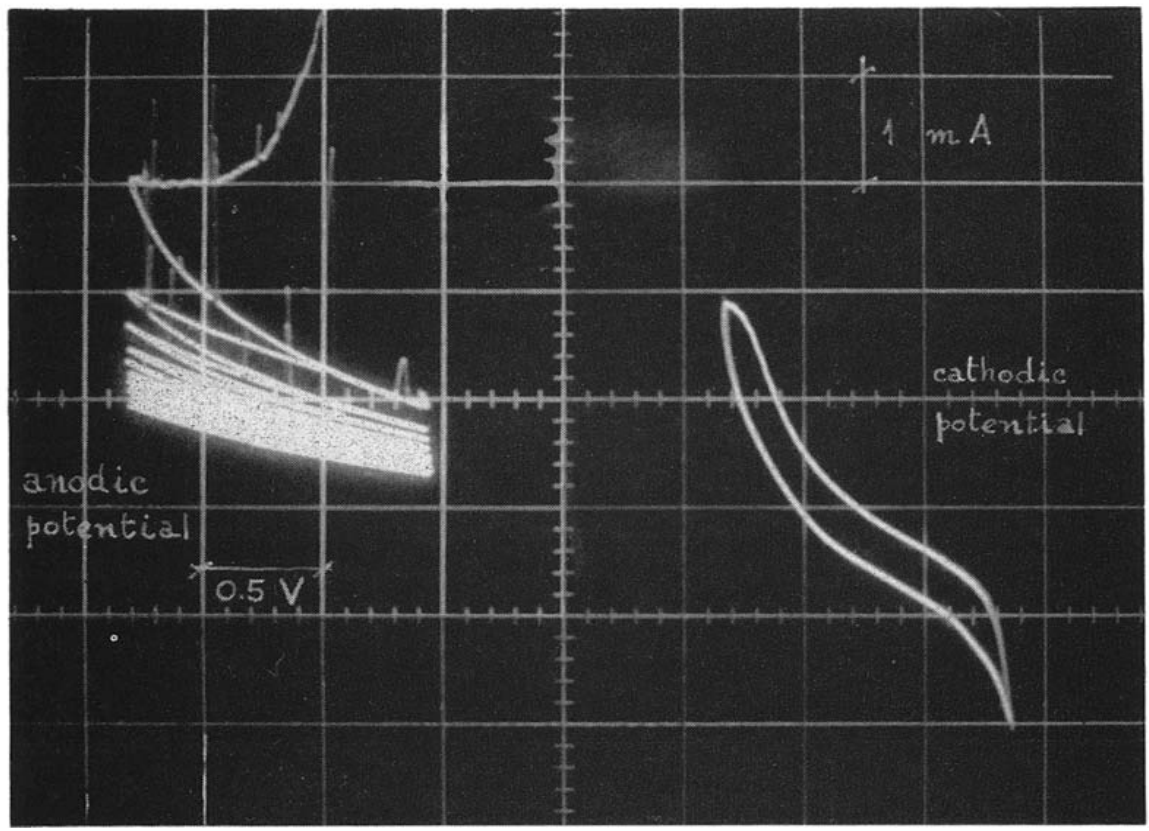

FIG. 8. Repetitive E/I curves showing the establishment of the passive film, as explained in the text. Potential-sweep rate $2.0 \mathrm{~V} / \mathrm{s}$. 
This conclusion was derived from the fact that the charge comprised during the $E / I$ display was perfectly reproducible and agreed with that already determined from potentiostatic $I / t$ experiments. ${ }^{5}$

Experiments with a constant repetitive potential sweep

These experiments were done with electrodes which were initially mechanically polished to a mirror surface. The first set of experiments comprised steady voltammetric $E \mid I$ curves displayed after repetitive cycles, covering a wide range of applied potential and rate of potential sweeping.

Let us consider a $E / I$ display at $0 \cdot 324 \mathrm{~V} / \mathrm{s}$ covering a potential difference of about $2.3 \mathrm{~V}$ extending $1.1 \mathrm{~V}$ towards the negative side of the rest potential and $1.2 \mathrm{~V}$ towards the positive side (Fig. 1). At positive potentials a definite anodic peak current exists which precedes the onset of a definite passivity on the electrode. When this region has been reached, the return half cycle towards negative potentials shows no cathodic peak at potentials more positive than the initial rest potential. At potentials more negative than the latter at least two cathodic current peaks are found and a small anodic current peak is observed.

If the negative potential limit of the sweep extends to higher negative potentials covering a potential range of $6.5 \mathrm{~V}$ (Fig. 2), three new anodic current peaks appear

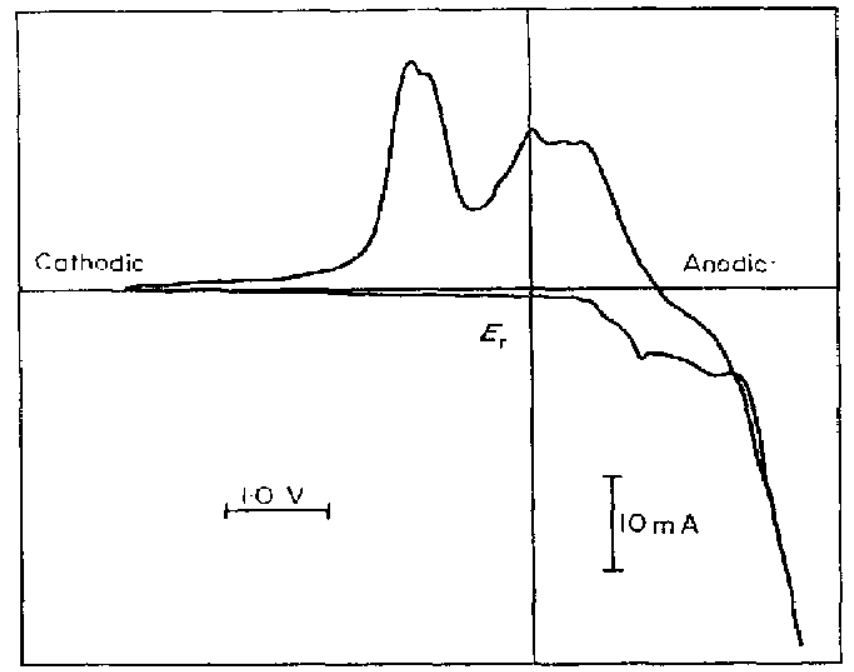

FIG. 2. Voltammetric $E / I$ curve obtained at $0 \cdot 463 \mathrm{~V} / \mathrm{s}$. Stationary platinum electrode. $190^{\circ} \mathrm{C}$.

when the potential is swept towards positive values. These three current peaks cover an area which is larger when the sweeping potential extends to more negative values. The location of the potentials at which the current maxima exist depends on the potential sweep rate.

The number of current peaks is reduced if the potential range is narrower and the sweep rate is increased. Thus, with a sweep rate of $3.07 \mathrm{~V} / \mathrm{s}$ covering a potential range of $3.4 \mathrm{~V}$ (Fig. 3), two well defined anodic current peaks are observed. Their potential difference is $1.25 \mathrm{~V}$. There are also various cathodic peaks, two of them appearing as shoulders. The maximum cathodic current is located at $1.0 \mathrm{~V}$ negative to the initial rest potential. 
With sweeps covering a large negative potential range, such as $2 \cdot 3 \mathrm{~V}$ negative to the initial rest potential, as shown in Fig. 4, a cathodic peak related to potassium electrodeposition is observed at $-1.5 \mathrm{~V}$. When this occurs, the shape of the return cycle is appreciably modified and the oxidation currents at negative potentials are significantly increased.

The above experiments do not allow a direct comparison of anodic and cathodic areas. However, the area enclosed by the largest anodic peak is nearly the same as that of the cathodic peak, for experiments covering, a potential range from $-1 \cdot 0-$ $1.6 \mathrm{~V}$, referred to the rest potential, and a potential sweep rate of $4.36 \mathrm{~V} / \mathrm{s}$ (Fig. 5). The integration of the anodic and cathodic areas yields $4.2 \times 10^{-4}$ and $3.2 \times 10^{-4} \mathrm{C}$ respectively. The voltammetric $E / I$ curves shown in Fig. 5 exhibit a large anodic current peak at positive potentials, which corresponds to the oxidation of thiocyanate ion, and also a smalier one at negative potentials. The cathodic peaks are located at negative potentials covering a wider potential range. Most of these runs at high potential sweep rates and low potential range covering nearly the same cathodic and anodic amplitudes exhibit a ratio of the anodic to the cathodic area between 1.0 and 1.5 or thereabouts. This indicates that the main cathodic process comprises the same quantity of electricity and suggests that the same number of charges per unit of reacting species participates in both processes.

On the other hand, the sweep rate has a definite influence on the current-peak locations. At low sweep rates the potential difference between the largest anodic current peak and the largest cathodic current peak is less than $2.0 \mathrm{~V}$, in coincidence with the polarogram eariier reported. ${ }^{3}$ The features described for the voltammetric $E / I$ curves are also valid if the platinum working electrode is rotated.

The potential difference between the anodic current maxima of the voltammetric $E / I$ curves coincides with the potential difference related to the transition time (as $\tau_{1 / 4}$ ) obtained with the reverse pulse experiments. ${ }^{5}$ Therefore, it is reasonable to assume that the first anodic peak at lower potentials, which corresponds to the first transition time of those experiments, is a diffusional peak and should correspond to the oxidation of products formed during the reduction of the film. The second transition time observed in the reverse pulse experiments, on the other hand, relates to the second anodic peak assigned to film formation.

\section{Experiments with a continuous shift of the base potential}

It is possible to obtain voltammetric $E / I$ curves by shifting the base potential continuously, starting from a steady situation at the electrode, either towards more positive or more negative values, and maintaining a constant amplitude (Figs. 6 and 7). The first picturc clearly shows how the passive state is attained. The maximum current related to the film formation shifts towards more negative potentials as the initial potential goes towards positive potentials, due to a pseudo-ohmic polarization. The same effect is observed with the anodic current peak located in the negative potential region. A reverse effect appears when the potential sweep moves from positive to negative potentials.

\section{Formation of the passive film on the electrode}

Let us consider now a reverse situation, that is, let us start with the working electrode under repetitive potential cycles covering only the cathodic region, until a 
steady state situation is reached (Fig. 8, right). Then, abruptly, the potential sweep is shifted towards potential regions located on the positive side of the initial electrode rest potential, covering the same voltage difference (Fig. 8, left). After the first cycle under the new experimental conditions, a systematic anodic current decrease is observed after repetitive cycles, related to the formation of the insoluble film on the electrode surface.

\section{Passivity breakdown}

Let us consider one experiment where the working electrode undergoes repetitive anodic cycles until the anodic current becomes negligible (Fig. 9, left). The cycles are

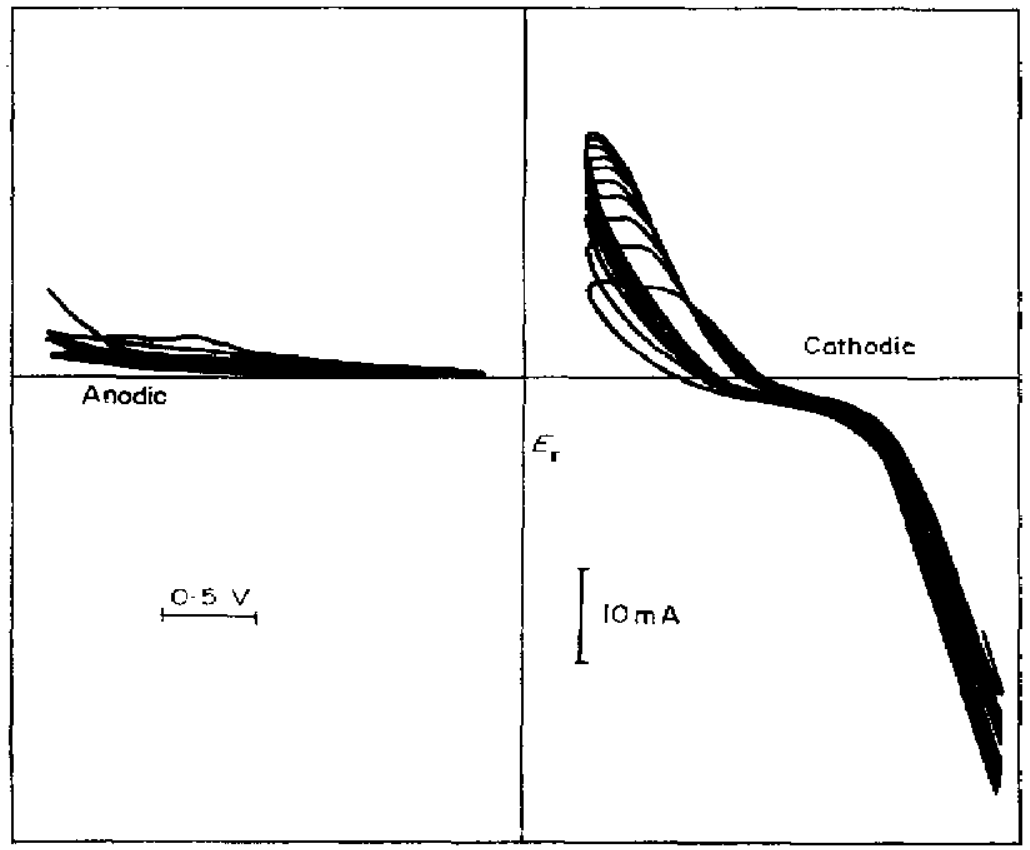

FIG. 9. Repetitive $E / I$ curves to show passivity breakdown when the potential sweep is shifted from the anodic to the cathodic region. Potential-sweep rate $1.95 \mathrm{~V} / \mathrm{s}$.

then instantaneously shifted to the negative potential region, comprising the same difference of potential (Fig. 9, right). During sweeping within the negative region, the cathodic current increases until a steady value is reached, which corresponds to the maximum cathodic current obtained after repetitive cycles. The magnitude of the cathodic current and the high negative potential reached under this circumstance indicate the probable discharge of potassium ion to potassium metal. In this case during the anodic half-cycle the oxidation of potassium takes place or the disappearance of the $(\mathrm{SCN})_{x}$ film may occur, if the latter is still present on the electrode surface. Therefore, the "cathodic cleaning" of the surface is mainly due to the occurrence of one of the reactions

or

$$
x \mathrm{~K}+(\mathrm{SCN})_{x}=x \mathrm{~K}^{+}+x \mathrm{SCN}^{-}
$$

$$
3 x \mathrm{~K}+(\mathrm{SCN})_{x}=3 x \mathrm{~K}^{+}+x \mathrm{~S}^{2-}+x \mathrm{CN}^{-} \text {. }
$$


These reactions explain the increase of anodic current peaks within the cathodic potential region, after electrolytic cleaning of the electrode surface.

\section{Voltammetric E/I curves. Single-sweep experiments}

General features. Single-sweep experiments were performed with working electrodes differently prepared and were particularly aimed at obtaining quantitative kinetic information which would allow a mechanistic interpretation of the electrode processes. Figure 10 shows three $E / I$ curves swept at $0.05 \mathrm{~V} / \mathrm{s}$ with a polished platinum

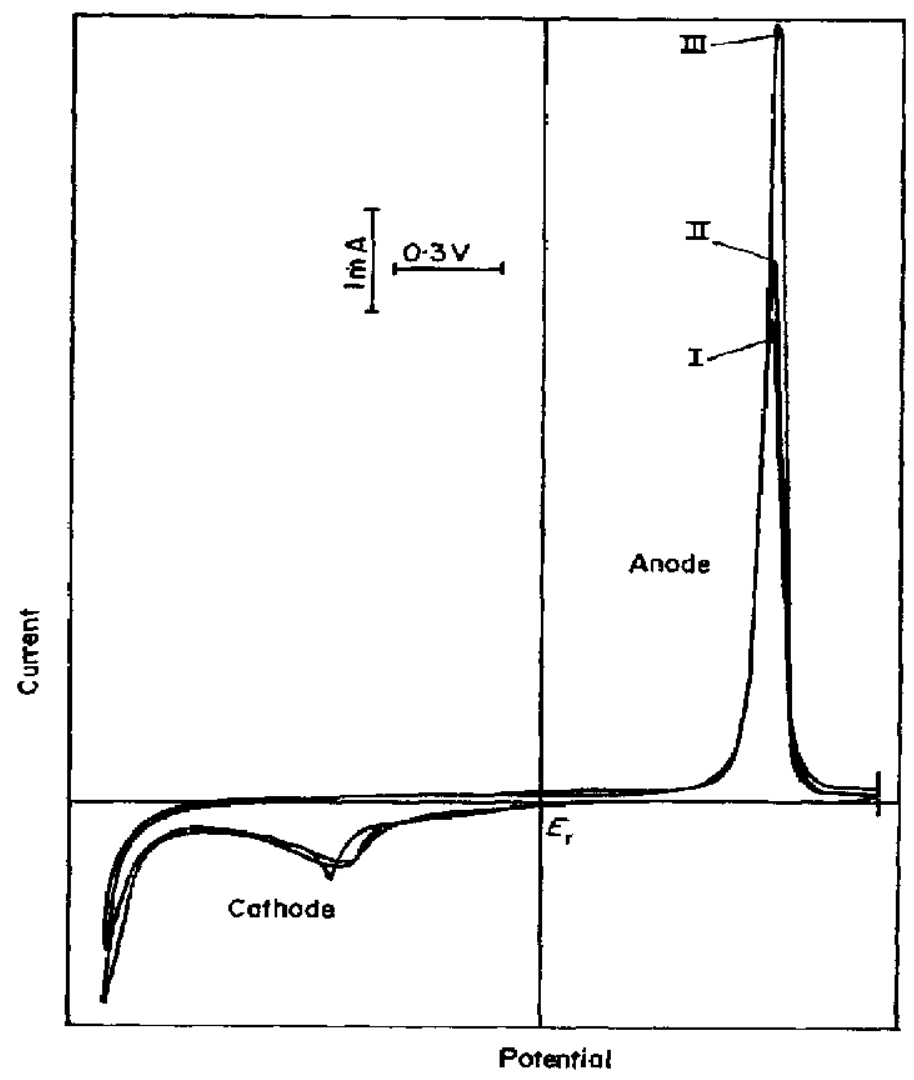

FIG. 10. Single-sweep voltammetric $E / I$ curves. Polished platinum-wire electrode. First, second and third sweeps are indicated as I, II and III, respectively. Potentialsweep rate $0 \cdot 05 \mathrm{~V} / \mathrm{s}$.

electrode, the first sweep starting from the rest potential, $E_{r}$. It differs from the following two mainly by the location, shape and definition of the cathodic maximum. The cathodic current probably embraces three ill-defined maxima, particularly for the second and third $E / I$ voltammetric curves. Besides, the anodic maximum increases during the successive sweeps, and consequently, the charge involved in the anodic half-cycle increases from $8.75 \times 10^{-3} \mathrm{C}$ in the first anodic half-cycle to $10.5 \times 10^{-3} \mathrm{C}$ in the third. The charge comprised in the cathodic half-cycle is difficult to evaluate. Its value however is estimated as being of the same order as that reported for the anodic half-cyclc. Figure 11 comprises two successive $E / I$ curves at the rate of $0.4 \mathrm{~V} / \mathrm{s}$. The first sweeping in the anodic direction presents the anodic current peak reported above. The second potential sweep covers a larger range of potential, extending to a more 


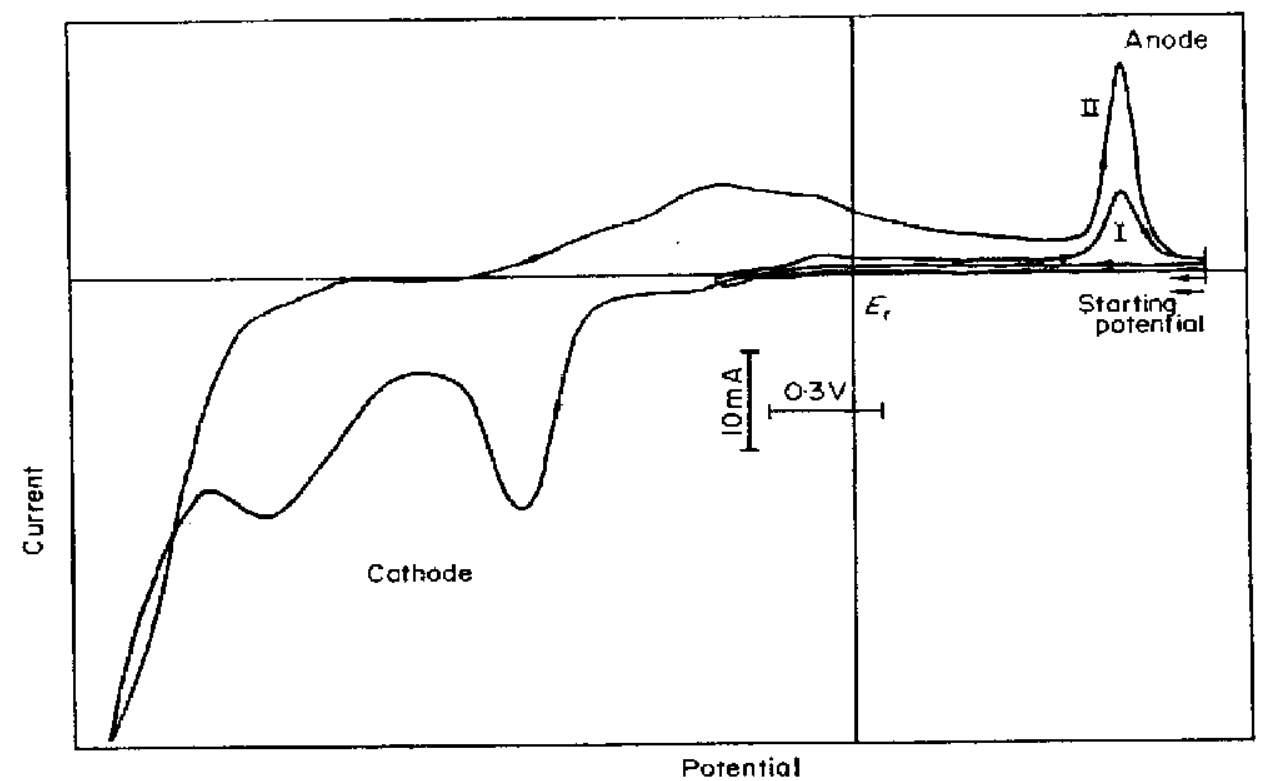

FrG. 11. Two consecutive voltammetric $E / I$ curves at different potential amplitudes. Potential sweeps are applied to platinum-wire electrodes already covered with the passivating film. Potential-sweep rate $0.4 \mathrm{~V} / \mathrm{s}$.

cathodic region. Under these circumstances at least three cathodic current peaks are observed, located at $-1.13,-1.63$ and $-2.31 \mathrm{~V}$ with respect to the potential corresponding to the anodic current maximum. It should also be observed that the anodic area of the major anodic current peak increases when large negative potentials have been reached. Besides, the second $E / I$ curve also exhibits two less well-defined anodic current peaks.

It is clear, as shown in Fig. 12, that, to obtain again the anodic current peak after the first cycle, it is necessary during the cathodic half cycle to reach a potential limit more negative than the initial rest potential. If this is not done the second or any successive cycle fails to give the anodic current peak, as the blocking substance is

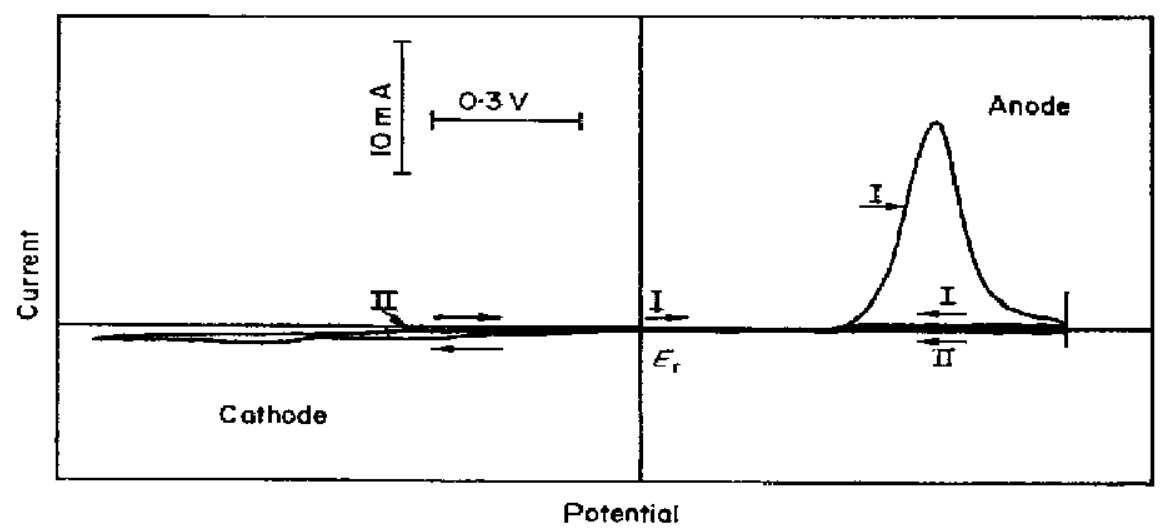

FIG. 12. First and second voltammetric $E / I$ curves obtained with polished platinumwire electrodes. The anodic current peak appears again during the second sweep if the cathodic potential limit exceeds the initial rest potential. Potential-sweep rate $0 \cdot 4 \mathrm{~V} / \mathrm{s}$. 
not removed from the electrode surface. But if the cathodic limit of the potential sweeps exceeds the initial rest potential, the anodic current peak exists and its area is about 70 per cent larger than the area covered when the electrode surface has been mechanically polished (Fig. 10). Figure 13 shows a set of $E / I$ curves obtained with an

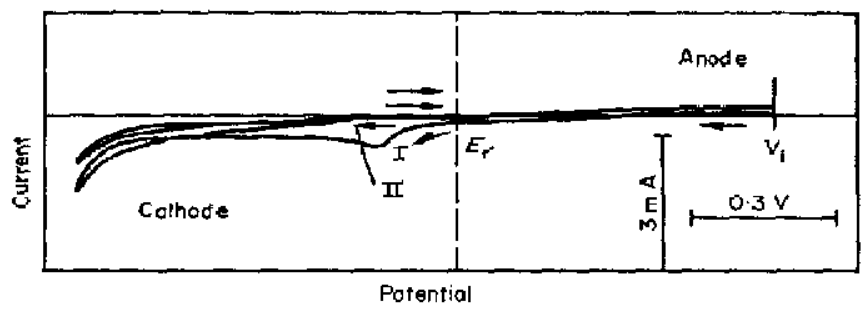

FIG. 13. Voltammetric $E / I$ curve obtained with a platinum-wire electrode covered by the passive film and running the experiment from the initial rest potential toward cathodic potentials. Potential-sweep rate $0-05 \mathrm{~V} / \mathrm{s}$.

electrode surface covered by the passive film and by running the experiments from the initial rest potential towards cathodic potentials. It is clear that the film disappears during the first cathodic half-cycle, since the cathodic peak related to film dissolution is no longer observed after the first cycle.

The cathodic current peak related to the dissolution of the film involves an area which only at the lowest potential sweeps is nearly the same as that of the anodic peak. At higher sweeping rates the cathodic area remains smaller than the anodic area (Fig. 14). Tables 1 and 2 show the charge involved in the anodic, $Q_{a}$, and cathodic, $Q_{\mathrm{o}}$, current maxima under different experimental conditions. As seen $Q_{\mathrm{a}}$ increases as the potential sweep rate increases, approaching, at high rates, nearly twice the value obtained at low rates. It should be noted, however, that the evaluated cathodic charge may be affected, particularly at low sweep rates, by the possible mechanical detachment of the insoluble film.

Table 1. Charge passed during a single potential sweep covering the REGION OP ANODIC AND CATHODIC CURRENT MAXIMA.

\begin{tabular}{ccc} 
PotentIAL-SWEEP AMPLITUDB: & $1.85 \mathrm{~V}$, ELECTRODE AREA : & $0.439 \mathrm{~cm}^{2} ; 190^{\circ} \mathrm{C}$ \\
\hline$v \times 10^{\mathrm{s}}$ & $Q_{\mathrm{a}} \times 10^{\mathrm{s}}$ & $Q_{0} \times 10^{\circ}$ \\
$\mathrm{V} / \mathrm{s}$ & $\mathrm{C}$ & $\mathrm{C}$ \\
\hline 5 & 13.3 & 13.8 \\
10 & 14.0 & $10 \cdot 6$ \\
50 & 15.6 & $10 \cdot 4$ \\
100 & 18.5 & 7.9 \\
500 & 19.5 & - \\
\hline
\end{tabular}

Table 2. Charge passed during a single potential SWEEP COVERING ONLY THE ANODIC CURRENT MAXTMA. PotentLAL-SWEeP AMPLITUde: $1.04 \mathrm{~V}$; RLECTRODE AREA: $0.439 \mathrm{~cm}^{2} ; 190^{\circ} \mathrm{C}$

\begin{tabular}{cc}
$v \times 10^{8}$ & $Q . \times 10^{3}$ \\
$\mathrm{~V} / 5$ & $\mathrm{C}$ \\
\hline 5 & 5.6 \\
10 & 5.5 \\
20 & 6.8 \\
50 & 7.4 \\
100 & 12.0 \\
200 & 17.0 \\
\hline
\end{tabular}




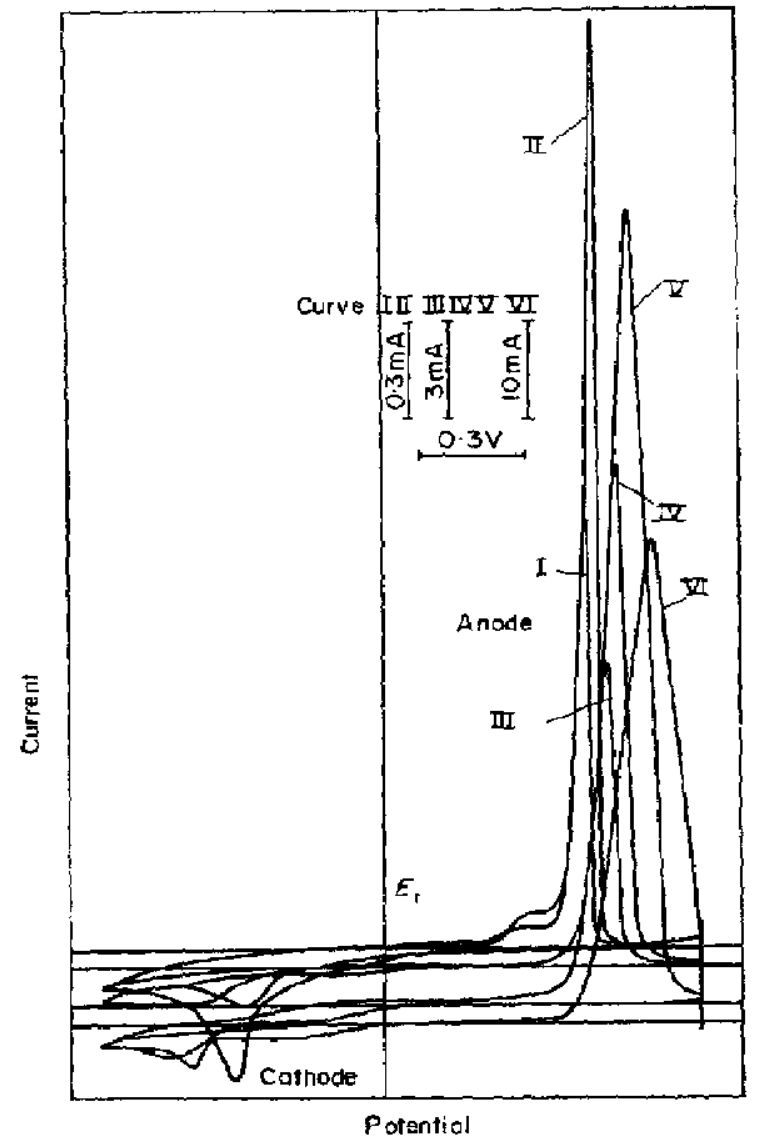

FIO. 14. Single sweep voltammetric $E / I$ curves obtained with freshly polished platinum wire electrodes at different sweep rates.

I, 0.005; T्र, 0.01; III, 0.05; IV, 0.1; V, 0.2; VI, 0.5 V/s.

Effect of sweep rate on the anodic current peak. Figure 15 corresponds to a set of $E / I$ curves, covering an anodic potential of $1.04 \mathrm{~V}$, each curve obtained at a definite potential-sweep rate, starting from a fresh electrode surface polished mechanically and at the same rest potential. The curves exhibit a net shift of the potential corresponding to the maximum anodic peak with the sweep rate and also an increase of the maximum anodic current with the sweep rate. As seen in Fig. 16, the potential, $V_{m}$, corresponding to the maximum anodic current changes linearly with the logarithm of the potential-sweep rate, $v$. At low sweep rates the slope of the best straight line approximates the value $2 \cdot 3(R T / 2 F) \mathrm{V}$ while at higher ones, it attains the value $2 \cdot 3(R T / F)$. On the other hand, the maximum anodic current related to film formation for initialfy polished platinum electrodes fits a reasonable linear relationship with the potential sweep rate, as illustrated in Fig. 17.

Effect of sweep rate on the cathodic peak related to passivity breakdown. As in the case of the anodic current peak, the cathodic current peak related to the dissolution of the passive film depends on the rate of potential sweeping. Thus, it is found that the potential related to the cathodic maximum current depends linearly on the logarithm of $v$ as seen in Fig. 18. As in the anodic case, the slope of the best straight line lies close to $2 \cdot 3 R T / F$ V. However, in this case no clcar-cut maximum-cathodic-current/ potential-sweep-rate relationship results, probably because the occurrence of a bulky 


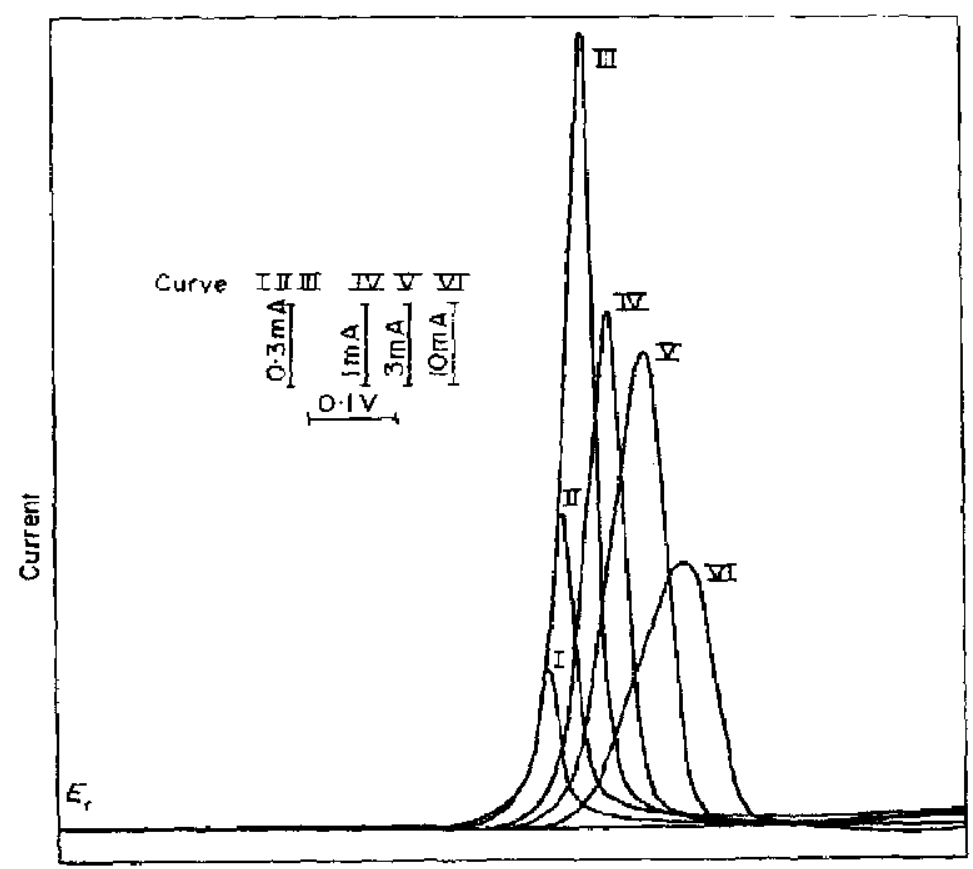

Fig. 15. Single-sweep voltammetric E/I curves obtained with polished platinum-wire electrodes at different sweep rates. I, 0.005; II, 0.01; III, $0 \cdot 02 ;$ IV, 0-05; V, 0.1; $\mathrm{VI}, 0.2 \mathrm{~V} / \mathrm{s}$.

Potential

Fro. 16. Semilogarithmic plot of the potential corresponding to the anodic current maximum os potential-sweep rate. Dotted lines correspond respectively to the slopes $2 \cdot 3(R T / 2 F)$ and $2 \cdot 3(R T / F) \mathrm{V}$.

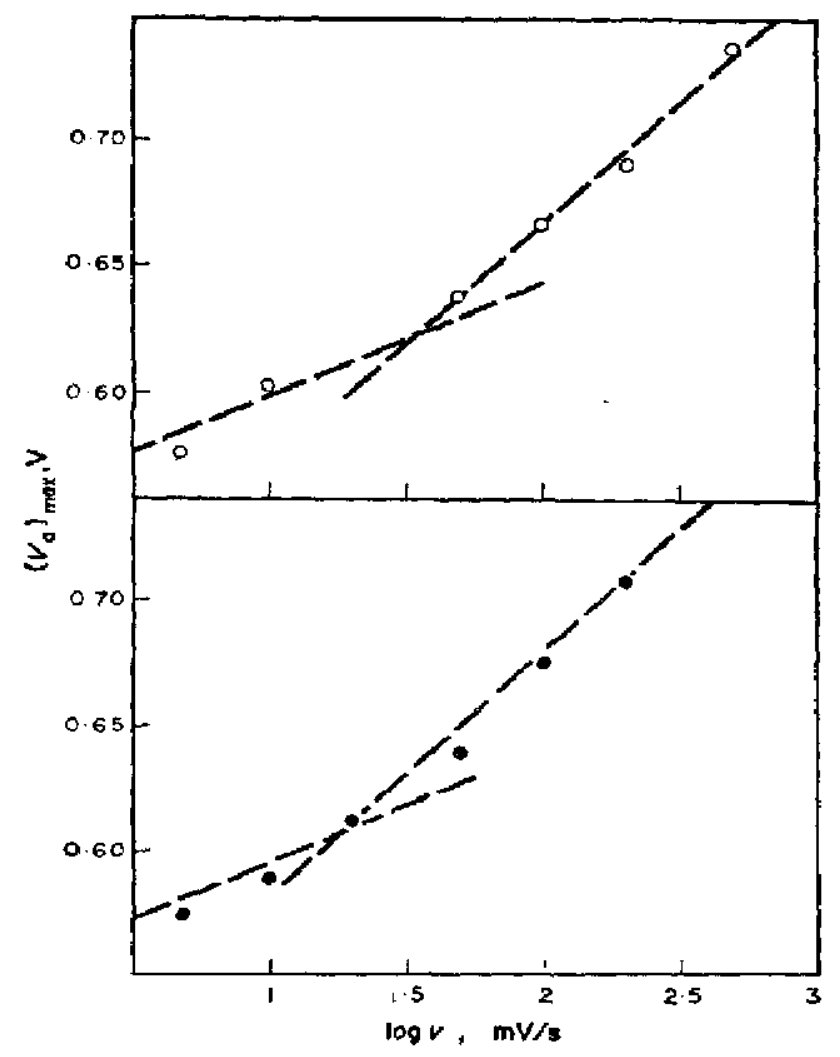




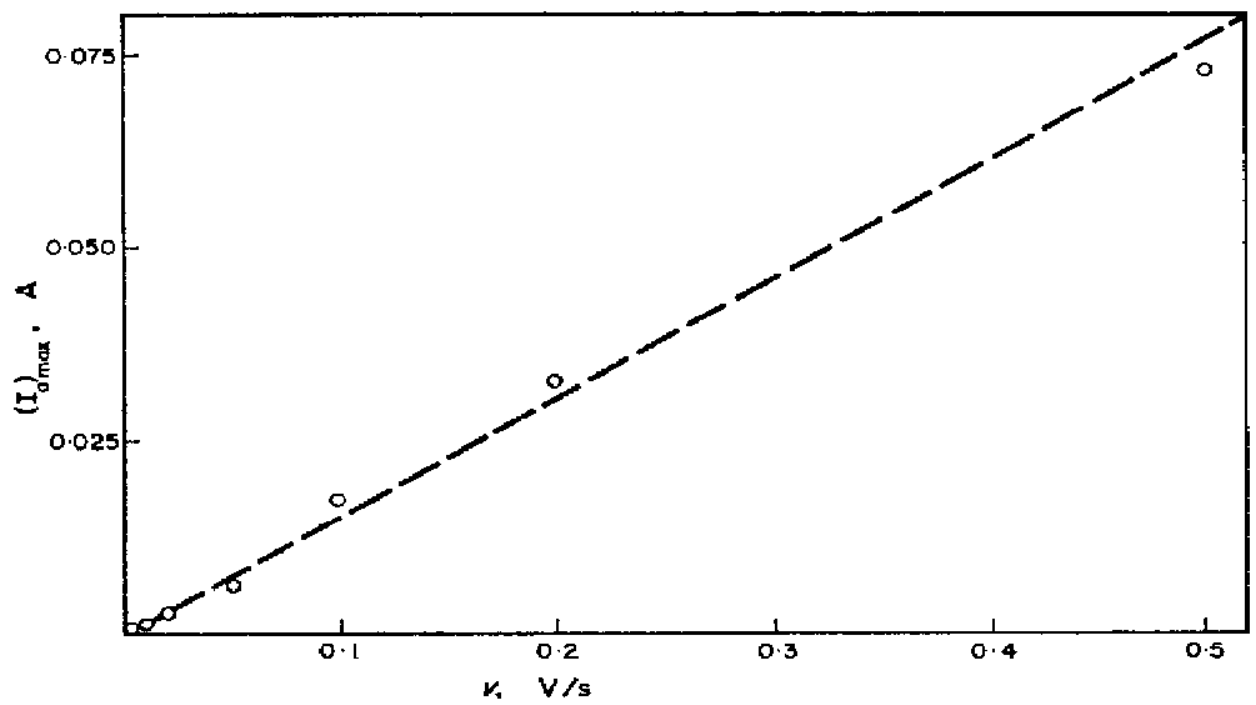

FIo. 17. Dependence of the maximum anodic current on the potential-sweep rate.

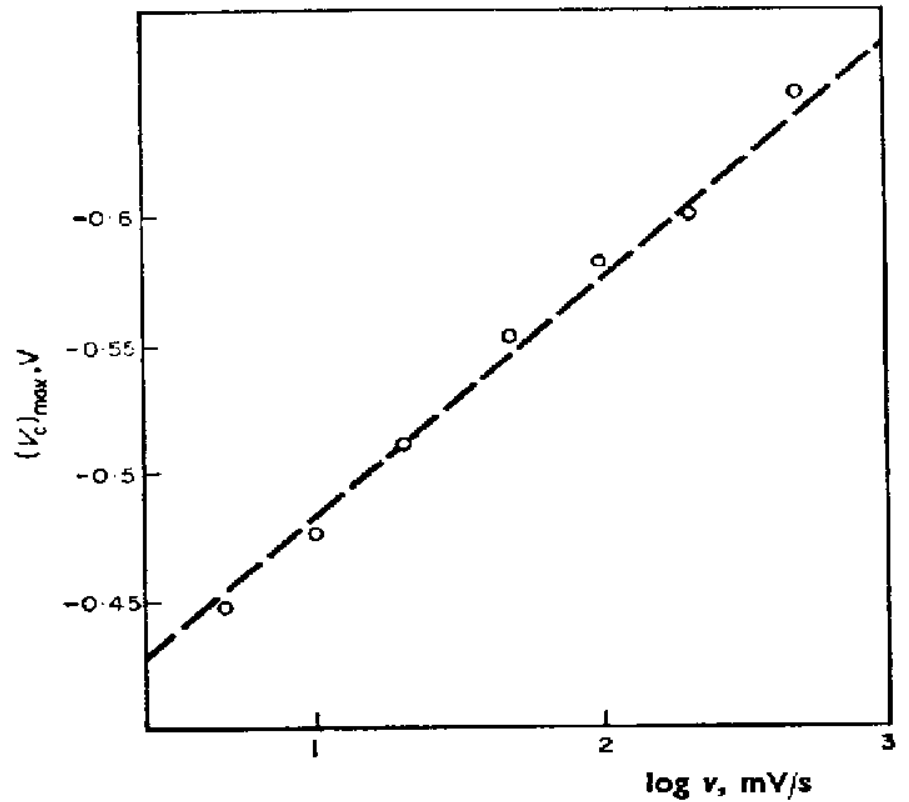

FIa. 18. Semilogarithmic plot of the potential corresponding to the cathodic current peak $v s$ potential-sweep rate. Dotted line corresponds to the slope $2 \cdot 3(R T / F) \mathrm{V}$.

separation of the film from the electrode surface. The extent of this perturbation seems to depend on the potential sweep rate in a rather complicated way.

\section{DISCUSSION}

Both under repetitive or single-sweep conditions, the main over-all reactions occurring at the electrodes are given as follows. For the anodic reactions

$$
x \mathrm{SCN}^{-}=(\mathrm{SCN})_{x}+x \mathrm{e},
$$

where parathiocyanogen constitutes an insoluble film on the electrode. The anodic current peak located at positive potentials is undoubtedly related to reaction $I$. 
Three possible electrode processes may be related to the cathodic half-cycle started at positive potentials, namely

and

$$
\begin{aligned}
(\mathrm{SCN})_{x}+x \mathrm{e} & =x \mathrm{SCN}^{-} \\
(\mathrm{SCN})_{x}+3 x \mathrm{e} & =x \mathrm{~S}^{2-}+x \mathrm{CN}^{-}
\end{aligned}
$$

$$
\mathrm{SCN}^{-}+2 \mathrm{e}=\mathrm{S}^{2-}+\mathrm{CN}^{-} \text {. }
$$

Reactions II and III comprise the cathodic dissolution of the film while reaction IV is the electrochemical reduction of the $\mathrm{SCN}^{-}$-ion. The occurrence of these reactions is related to the three anodic current peaks which partially overlap, at negative potentials, during the half-cycle potential sweep toward the negative potentials. They correspond respectively to the oxidation of $\mathrm{S}^{2-}, \mathrm{CN}^{-}$and $\mathrm{SCN}^{-}$ions. The oxidation of the former occurs at more negative potentials and the area involved in the voltammetric $E / I$ display is the largest one of the three above mentioned peaks since the overall reaction comprises two unit charges per ion.

Of the different experimental results, however, those obtained under single-sweep conditions are more significant and should be considered in the first place, as they permit at least a mechanistic interpretation of the film-formation process. Information gathered from repetitive voltammetry, particularly that resulting at high potential sweeps, although it pertains to the same electrode processes, corresponds to a rather different electrode condition and, therefore, will be discussed independently further on.

\section{The likely reaction mechanisms for parathiocyanogen formation}

As earlier reported in a previous paper, ${ }^{5}$ the electrochemical formation of the passivating film on platinum anodes when molten potassium thiocyanate is electrolysed, is a process which at the earlier stage is under film-growth rate control. ${ }^{8}$ The present results demonstrate once more that the anodic electrode reaction should be considered as a frankly irreversible process, which is represented by Tafel rate equations whose slopes are $R T / 2 F$ and $R T / F$ at low and at high potential sweep rates respectively. Therefore it seems as if the reaction mechanism changes as the potential sweeping rate is increased.

A possible mechanism for the reaction at low potential-sweep rates. The reaction kinetics yielding the Tafel slope $R T / 2 F$ can be explained in terms of the reaction scheme postulated to interpret the results derived from potentiostatic transients, ${ }^{6}$ that is:

Mechanism I:

$$
\begin{gathered}
\mathrm{Pt}+\mathrm{SCN}^{-}=\mathbf{P t}(\mathrm{SCN})+\mathrm{e} \\
\mathbf{P t}(\mathrm{SCN})+\mathrm{Pt}^{*}=\mathbf{P t}^{*}(\mathrm{SCN})+\mathbf{P t} \\
\mathrm{Pt}^{*}(\mathrm{SCN})_{s}+\mathbf{P t}(\mathrm{SCN})=\mathbf{P t}^{*}(\mathrm{SCN})_{\infty+1}+\mathbf{P t}
\end{gathered}
$$

$\mathrm{Pt}^{*}$ represents a nucleation centre and the occurrence of either steps $\mathrm{Ib}$ or Ic depends on the extent of the electrode surface coverage. 
At any time, $t$, let us assume that the rate of film growth is given by the faradaic current density, $i$, which is proportional to the rate of change of the electrode area $A,{ }^{5}$

$$
i=\frac{z F \rho \delta}{M} \frac{\mathrm{d} A}{\mathrm{~d} t},
$$

where $z$ is the number of electrons per mole of reacting species whose molecular weight is $M, \rho$ the density of the passivating film and $\delta$ its thickness when the free electrode area, $A$, is covered. Let us call $\theta$ the total degree of surface coverage by the intermediates formed in the electron-transfer step, so that $A$ is proportional to $(1-\theta)$. At a constant potential, $A$, and consequently $(1-\theta)$, are exponential functions of time as already indicated..$^{5}$ Assuming that the latter partial reaction is under quasiequilibrium and that Langmuir-isotherm conditions for the adsorbed intermediate prevails, we have

$$
k_{i}(1-\theta) \exp \left[\frac{\alpha F V}{R T}\right]=k_{-i} \theta \exp \left[\frac{-(1-\alpha) F V}{R T}\right],
$$

where $k_{i}$, is the formal rate constant of step $i ; \alpha$ is the transfer coefficient assisting the electrode reaction in the forward direction and $V$ is the applied potential at the reaction interface, which changes linearly with time,

$$
V=V_{1}+v t
$$

$V_{\mathrm{i}}$ is the initial sweeping potential limit and $v$ its rate of change.

Let the surface diffusion of the intermediate towards the reacting nuclei now be rate-determining as expressed by step $\mathrm{Ib}$, and let us call the concentration of active nuclei, $c_{*}{ }^{\mathrm{B}}$. The rate equation in terms of current density, assuming the reaction is then completely irreversible, without any influence of the cathodic reaction, is

$$
i=k_{\mathrm{Ib}} c_{*}^{\mathrm{s}} \theta \text {. }
$$

After replacing the surface coverage by reaction intermediate from (2) to (4) we get

$$
i=K_{\mathrm{I}} k_{\mathrm{Ib}}(1-\theta) c_{*}{ }^{\mathrm{s}} \exp \left[\frac{F V}{R T}\right] \text {. }
$$

Equation (5) includes the surface concentration of reacting centres on the electrode. Let us assume that the distribution of those centres follows the Maxwell-Boltzmann statistics, and that the surface concentration, as expressed by $c_{*}{ }^{5}$, is a function of the potential applied at the interface,

$$
c_{*}{ }^{*}=c_{*}^{\circ} \exp \left[\frac{F V}{R T}\right]
$$

where $c_{*}{ }^{\circ}$ is a constant which gives the surface concentration of active centres when $V=0$. Thus, from (5) and (6),

$$
i=K_{\mathrm{I}} k_{\mathrm{Ib}} c_{*}^{\circ}(1-\theta) \exp \left[\frac{2 F V}{R T}\right] \text {. }
$$

In order to interpret the anodic current peak observed in the voltammetric $E / I$ curves, we follow the procedure already indicated for conventional potential-sweep voltammetry, and write

$$
\frac{\mathrm{d} i}{\mathrm{~d} t}=k^{\prime} \exp \left[\frac{2 F V}{R T}\right]\left[(1-\theta) \frac{2 F v}{R T}-\frac{\mathrm{d} \theta}{\mathrm{d} t}\right]=0,
$$


where

For (3) to be valid

$$
k^{\prime}=K_{\mathrm{I}} k_{\mathrm{Ib}} c_{*}^{\circ} \text {. }
$$

$$
\frac{\mathrm{d} \theta}{\mathrm{d} t}=(1-\theta) \frac{2 F v}{R T} .
$$

From (1) and (10), with the relationship between $A$ and $\theta$, the following expression for the maximum anodic current $\left(i_{m}\right)_{\text {tax }}$ is obtained,

$$
\left(i_{\mathrm{a}}\right)_{\max }=\frac{2 z F^{2} \rho \delta_{1}}{M R T}(1-\theta) v,
$$

and $\delta_{\mathbf{I}}$ is the average thickness of the film when the whole electrode area is covered, under the assumption that step Ib is rate-determining.

According to this equation, the anodic peak current depends linearly on the potential-sweep rate. This relationship is in principle fitted by the results. An explicit expression for the potential related to the maximum anodic current, $\left(y_{n}\right)_{\max }$, is obtained by (7) and (11),

$$
\left(V_{\mathrm{a}}\right)_{\max }=\frac{R T}{2 F} \ln \frac{2 z F^{2} \rho \delta_{\mathrm{I}}}{k^{\prime} M R T}+\frac{R T}{2 F} \ln v .
$$

This equation, which predicts a linear $\left(V_{\mathrm{a}}\right)_{\max } / \log v$ relationship with a slope equal to $R T / 2 F$, is approached by the experimental results at low sweep rates. Equations (11) and (12) however indicate the current and potential only at the anodic peak. It is convenient to derive a more general expression that could explain the shape of the whole voltammetric $E / I$ curve, following the theoretical procedure indicated for potential-sweep voltammetry. ${ }^{9}$ From (1), (7) and (3) the rate of film growth can be written

and

$$
\frac{z F \rho \delta_{1}}{M} \frac{\mathrm{d} \theta}{\mathrm{d} t}=k^{\prime}(1-\theta) \exp \left[\frac{2 F V_{1}}{R T}\right] \exp \left[\frac{2 F v t}{R T}\right]
$$

$$
-\mathrm{d} \ln (1-\theta)=\frac{k^{\prime} M R T}{z F^{2} \rho \delta_{1}} \exp \left[\frac{2 F V_{1}}{R T}\right] \exp \left[\frac{2 F v t}{R T}\right] \mathrm{d} t .
$$

After integrating (14)

$$
-\ln (1-\theta)=\frac{k^{\prime} M R T}{2 z F^{2} \rho \delta_{\mathrm{I}} v} \exp \left[\frac{2 F V_{i}}{R T}\right] \exp \left[\frac{2 F v t}{R T}\right]+J
$$

To evaluate the integration constant $J$, the boundary condition is: $t=0, \theta=0$. Thus,

and (10) becomes

$$
J=-\frac{k^{\prime} M R T}{2 z F^{2} \rho \delta_{1} v} \exp \left[\frac{2 F V_{1}}{R T}\right]
$$

$$
-\ln (1-\theta)=\frac{k^{\prime} M R T}{2 z F^{2} \rho \delta_{I} v} \exp \left[\frac{2 F V_{i}}{R T}\right]\left[\exp \left(\frac{2 F v t}{R T}\right)-1\right] .
$$

From (7) and (17), we have finally

$$
\ln i=\ln k^{\prime}-\frac{k^{\prime} M R T}{2 z F^{2} \rho \delta_{1} v} \exp \left[\frac{2 F V_{1}}{R T}\right]\left\{\exp \left[\frac{2 F\left(V-V_{1}\right)}{R T}\right]-1\right\}+\frac{2 F V}{R T} .
$$


As a limiting case, (18) yields a simple steady-state theoretical Tafel line with a slope equal to $R T / 2 F$ when $v=0$. Equation (18) describes the over-all anodic voltammetric $E / I$ curve, obtained at low potential sweeping rates, as shown in Fig. 19.

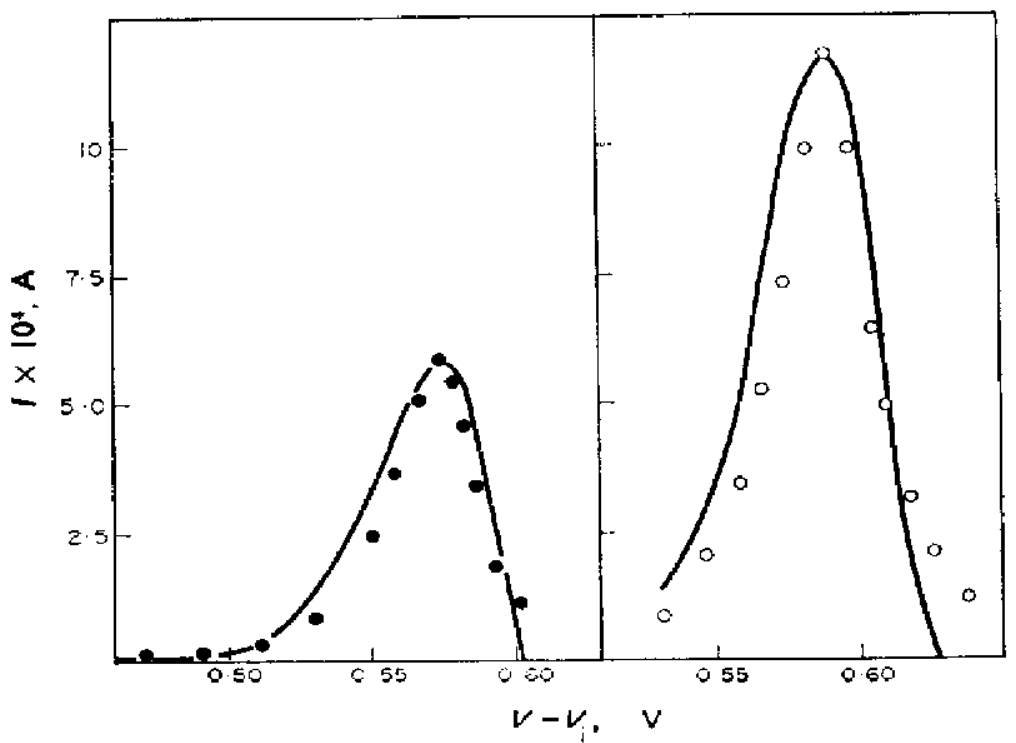

FrG. 19. Voltammetric $E / I$ curves obtained with equation (19) at potential-sweep rates of $0.05 \mathrm{~V} / \mathrm{s}(O)$ and $0.01 \mathrm{~V} / \mathrm{s}(0)$. Points refer to experimental results.

Parameters used in the calculations are compiled in Table 3. The kinetic parameters derived from single sweep $E / I$ curves are assembled in Table 4. A comparison of the quantity of electricity related to film formation with values calculated for different film thicknesses is shown in Table 5.

Let us find now the expression for $\left(i_{\mathrm{a}}\right)_{\max }$ derived from (18). Thus when $i=\left(i_{\mathrm{a}}\right)_{\max }$, $V=\left(V_{\mathrm{a}}\right)_{\max }$ and

$$
\ln \left(i_{\mathrm{u}}\right)_{\max }=\ln \frac{2 z F^{2} \rho \delta_{1}}{M R T} v+\left[\frac{k^{\prime} M R T}{2 z F^{2} \rho \delta_{1} v} \exp \left(\frac{2 F V_{1}}{R T}\right)-1\right] .
$$

The second term of the right-hand member of (19) approaches -1 , when

$$
\frac{k^{\prime} M R T}{2 z F^{2} \rho \delta_{\mathrm{I}} v} \exp \left(\frac{2 F V_{1}}{R T}\right) \ll 1 .
$$

This situation can be approximated by increasing the rate of the potential sweeping, although it is reasonable to assume that in the present circumstances, the ratio $k^{\prime} / \delta_{I}$ is small enough to make the pre-exponential term negligible at any potential sweeping rate used in the experiments. With this assumption, (19) becomes

$$
\ln \left(i_{\mathrm{a}}\right)_{\max }=\ln \frac{2 z F^{2} \rho \delta_{\mathrm{I}} v}{M R T}-1,
$$

or in a simpler expression

$$
\left(i_{a}\right)_{\max }=\frac{1}{e} \frac{2 z F^{2} \rho \delta_{1}}{M R T} v
$$


Table 3. Parameters for calculation of the E/I voltammetruc curves. ELECTRODE AREA : $0.439 \mathrm{~cm}^{2} ; 190^{\circ} \mathrm{C}$

\begin{tabular}{ccc}
$v \times 10^{*}$ & $\left(I_{\mathrm{a}}\right)_{\max } \times 10^{8}$ & $(V \mathrm{a})_{\max } \times 10^{9 *}$ \\
$\mathrm{~V} / \mathrm{s}$ & 0.59 & 575 \\
5 & 1.18 & 590 \\
10 & 2.94 & 616 \\
20 & 6.41 & 641 \\
50 & 17.85 & 675 \\
100 & 33.0 & 707 \\
200 & 26.1 & 708 \\
$200 \dagger$ & 73.3 & 773 \\
500 & & \\
\hline
\end{tabular}

* Referred to the initial potential.

$\uparrow$ Cathodic cleaning.

TAble 4. Parameters derived from single-sweep El $I$ Curvis. $190^{\circ} \mathrm{C}$

\begin{tabular}{|c|c|c|c|c|c|c|}
\hline$v \underset{V / s}{\times 10^{3}}$ & $\underset{C / \mathrm{cm}^{2}}{\left(z F_{\rho} \delta / M\right)^{2}} \times 10^{2}$ & $\underset{\mathrm{C} / \mathrm{cm}^{\mathrm{a}}}{\left(z F_{p} \delta_{\mathrm{II}} / M\right)} \times 10^{\mathrm{a}}$ & $\begin{array}{c}k^{\prime} \times 10^{18} \\
\mathrm{~A} / \mathrm{cm}^{2}\end{array}$ & $\begin{array}{c}k^{*} \times 10^{3} \\
\mathrm{~A} / \mathrm{cm}^{2}\end{array}$ & $\underset{\mathrm{V}}{R T / 2 F}$ & $\underset{V}{R T / F}$ \\
\hline 5 & $1 \cdot 43$ & - & $5 \cdot 7$ & - & 0.0195 & - \\
\hline 10 & 1.43 & - & $5 \cdot 3$ & - & 0.0195 & - \\
\hline 20 & 1.78 & - & 3.5 & $\ldots$ & 0.0195 & - \\
\hline 100 & $\ldots$ & $4 \cdot 42$ & - & 3.8 & - & $0 \cdot 040$ \\
\hline 200 & - & $4 \cdot 10$ & - & $2 \cdot 4$ & - & 0.040 \\
\hline $200^{*}$ & - & $3 \cdot 25$ & - & 1.9 & - & 0.040 \\
\hline 500 & - & 3.63 & - & 1.9 & - & 0.040 \\
\hline
\end{tabular}

* Cathodic cleaning.

TABle 5. Values of $z F \rho \delta / M$ FOR $\rho=2 \mathrm{~g} / \mathrm{cm}^{2}, z=1$ AND $M=58$, FOR DIFFERENT $\delta$

\begin{tabular}{cc}
$\begin{array}{c}\delta \times 10^{8} \\
\mathrm{~cm}\end{array}$ & $\begin{array}{c}(z F \rho \delta / M) \times 10^{2} \\
C / \mathrm{cm}^{2}\end{array}$ \\
\hline 300 & 1.00 \\
400 & 1.33 \\
500 & 1.67 \\
600 & 2.00 \\
800 & 2.66 \\
1000 & 3.33 \\
\hline
\end{tabular}

Now equation (22) can be quantitatively tested as the slope of the $\left(i_{\mathrm{a}}\right)_{\max } v s v$ plot can be calculated since the terms it embraces are all known from independent experiments such as those potentiostatic current/time response already reported. ${ }^{5}$ The theoretical $\left(i_{a}\right)_{\max } / v$ line has been drawn in Fig. 17 . As seen there, at low sweep rates the coincidence between theory and experiments is satisfactory.

The possible reaction mechanism at high potential-sweep rates. When the potentialsweep rate is increased, a sweep rate can be reached at which the radical formed during the electron-transfer step has no time to diffuse towards a reacting centre at the surface. Thus, the electrode surface presents both $\mathbf{P t}$ and $\mathbf{P t}^{*}$ centres as indistinguishable from the standpoint of the film-growth process. Film formation therefore 
follows a different reaction scheme, expressed as follows:

Mechanism II

$$
\begin{aligned}
\mathrm{Pt}\left[\mathrm{Pt}^{*}\right]+\mathrm{SCN}^{-} & =\mathbf{P t}\left[\mathrm{Pt}^{*}\right](\mathrm{SCN})+\mathrm{e} \\
\mathbf{P t}\left[\mathrm{Pt}^{*}\right](\mathrm{SCN}) & \rightarrow \text { film formation. }
\end{aligned}
$$

This reaction scheme implies that either thiocyanate-ion discharge or film growth takes place indiscriminately on a Pt or a Pt* site. From the assumption of a quasiequilibrium for step IIa, under Langmuir-isotherm conditions, an expression similar to (3) results, and if reaction IIb is rate-determining, the rate equation, after neglecting the backward reaction, is

$$
i=k_{\mathrm{IIb}} \theta \text {. }
$$

After replacing $\theta$ [from (2)] in (23) we obtain

$$
i=K_{\mathrm{II}} k_{\mathrm{Ibb}}(1-\theta) \exp \left[\frac{F V}{R T}\right] \text {. }
$$

Therefore, the anodic current peak is defined by the null derivative of (24), namely

$$
\frac{\mathrm{d} i}{\mathrm{~d} t}=k^{\prime \prime} \exp \left[\frac{F V}{R T}\right]\left[(1-\theta) \frac{v F}{R T}-\frac{\mathrm{d} \theta}{d t}\right]=0,
$$

where

$$
k^{\prime \prime}=K_{\mathbf{I I}} k_{\mathrm{IIh}} .
$$

Equation (25) holds, when $\theta<1$, if

$$
\frac{\mathrm{d} \theta}{\mathrm{d} t}=(1-\theta) \frac{v F}{R T} .
$$

From (1) and (27), the maximum anodic current is given by

$$
\left(i_{\mathrm{a}}\right)_{\max }=\frac{z F^{2} \rho \delta_{\mathrm{II}}}{M R T}(1-0) v,
$$

where $\delta_{\text {II }}$ corresponds now to the film thickness covering the whole electrode area, on the assumption that step IIb is rate-determining. Again, a simple linear $\left(i_{\mathrm{a}}\right)_{\max } v s v$ relationship is obtained, as in the previous mechanism, although the slope of the straight line is different. Results obtained at higher sweep rates follow (28), rather satisfactorily.

Following the procedure already indicated, the expression for the potential at the maximum anodic current is

$$
\left(V_{\mathrm{a}}\right)_{\max }=\frac{R T}{F} \ln \frac{z F^{2} \rho \delta_{\mathrm{II}}}{k^{\prime \prime} M R T}+\frac{R T}{F} \operatorname{In} v .
$$

The $\left(V_{a}\right)_{\max } v s \ln v$ relationship involves the slope $R T / F$, which is actually approached by the experimental results.

The general equation for the $E / I$ voltammetric curves results from (1), (24) and (4),

$$
\frac{z F \rho \delta_{\mathrm{II}}}{M} \frac{\mathrm{d} \theta}{\mathrm{d} t}=k^{\prime \prime}(1-\theta) \exp \left[\frac{F V_{1}}{R T}\right] \exp \left[\frac{F v t}{R T}\right] .
$$


After rearranging (30) and integration as already indicated, we get

$$
\ln i=\ln k^{n}-\frac{k^{\alpha} M R T}{z F^{2} \rho \dot{\delta}_{11} v} \exp \left[\frac{F V_{i}}{R T}\right]\left\{\exp \left[\frac{\left(V-V_{1}\right) F}{R T}\right]-1\right\}+\frac{F V}{R T} .
$$

This equation has been tested with the $E / I$ curves obtained at the highest potentialsweep rates. For these experiments, as for those obtained at lower sweep rates, any contribution from the double layer current is neglected. At high sweep rates, however, as the currents are higher too, a significant correction for a pseudo-ohmic polarization contribution is not discarded. The ohmic resistance for the molten system may change from $0.1 \Omega$ at the initiation of the sweep to maximum of about $1.4 \Omega$ at the upper potential limit of the sweep. Therefore, at the maximum anodic current, assuming an approximate linear variation of the resistance with time, it was taken as $0.7 \Omega$. As seen in Fig. 20, the coincidence of the theoretical equation with results is quite

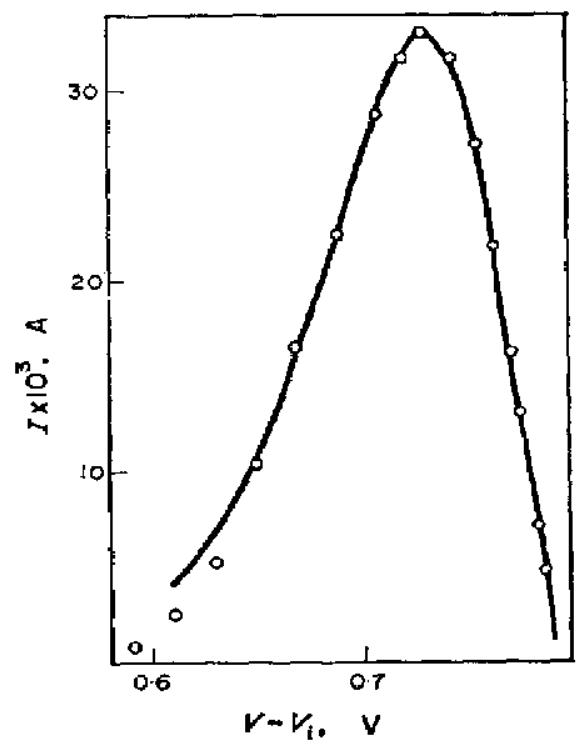

FIG. 20. Voltammetric E/I curve obtained with equation (31) at potential-sweep rate of $0.2 \mathrm{~V} / \mathrm{s}$. Points refer to experimental results.

reasonable. The kinetic parameters obtained from this reaction model are assembled in Table 3.

Finally, from (31), when $i=\left(i_{\mathrm{s}}\right)_{\max }$ and

the expression for $\left(i_{\mathrm{a}}\right)_{\max }$ is

$$
\frac{k^{n} M R T}{2 F^{2} p \delta_{\mathrm{II}} v} \exp \left(\frac{F V_{1}}{R T}\right) \ll 1,
$$

$$
\left(i_{\alpha}\right)_{\max }=\frac{1}{e} \frac{z F^{2} \rho \delta_{\mathrm{II}}}{M R T} v .
$$

It again yields a linear $\left(i_{\Omega}\right)_{\max }$ vs $v$ relationship.

The equations derived in the preceding paragraphs, although they correspond to a complex electrochemical reaction, are formally equivalent to those previously reported for voltammetric $E / l$ curves under Tafel conditions for a simple electrode 
process involving one-electron transfer and the formation of an adsorbed reaction intermediate obeying the Langmuir adsorption isotherm. ${ }^{9}$ Thus, a parallelism emerges between the rate constants related to the film growth process and those of the much simpler electrochemical reaction. This kinetic treatment therefore, seems to be quite relevant for a mechanistic interpretation of anodic film formation.

\section{Derivations from mechanisms (I) and (II)}

Any of the equations presented above which imply a relationship between $\left(i_{\mathrm{a}}\right)_{\max }$ and $v$ allows the calculation of the apparent electrode differential pseudocapacitance, $C_{\text {g, }}$ since

$$
C_{\mathrm{s}}=\frac{\left(i_{\mathrm{s}}\right)_{\max }}{v} .
$$

Results mentioned in Fig. 17 indicate that $C_{\mathrm{B}}$ is reasonably constant for experiments done at any potential-sweep rate. This means that as a first approximation the following relationship is valid,

$$
\frac{2 z F \rho \delta_{\mathrm{I}}}{M R T}=\frac{z F \rho \delta_{\mathrm{II}}}{M R T},
$$

as derived from (11) and (29). For (35) to be fulfilled the thickness of the film formed under conditions of Mechanism I must be one half the thickness of the film formed under Mechanism II. Since both film thicknesses are directly proportional to the charges passed, one should expect that for the anodic reaction under Mechanism I the charge passed would be half the charge passed for the process occurring according to Mechanism II.

The increase of charge passed with the potential-sweep rate can be interpreted as a tendency of the nuclei to grow with a larger curvature as the rate is increased. At low potential-sweep rates the growth is predominantly bidirectional while at larger ones it becomes predominantly three-dimensional. This is also a consequence of the mechanisms prevailing during the film-growth process.

Another interesting result is obtained from the ratio of either (11) and (22) or (24) and (33). Thus,

$$
\frac{1-\theta}{e}=1
$$

That is, the degree of surface coverage at the anodic maximum in the $E / I$ curves is 0.63 . This figure can immediately be checked with the free electrode area $A$, available at the potentiostatic current/time maximum reported earlier, ${ }^{5}$ which was equal to 0-38. Since $A=1-\theta$, the coincidence of the results is certainly good.

From the ratio $k^{\prime} \mid k^{\prime \prime}$ we have

$$
\frac{k^{\prime}}{k^{\prime \prime}}=\frac{K_{\mathrm{I}} k_{\mathrm{Ib}} c_{*}{ }^{0}}{K_{\mathrm{II}} k_{\mathrm{IIb}}}
$$

According to this equation, if the concentration of reacting nuclei on the platinum surface at $V=0$ is estimated as $10^{9}$ sites $/ \mathrm{cm}^{2}$, and $K_{\mathrm{I}} \approx K_{\mathrm{II}}$, the ratio of the rate constants $k_{\pi \mathrm{b}} / k_{\mathrm{IIb}}$ is of the order of $10^{8}$, a reasonable figure from the kineticstandpoint. It must be mentioned, however, that the number of reacting nuclei may be expected to be a function of the previous treatment of the electrode surface: one should expect 
therefore that the kinetic parameters, particularly those defined at the maximum of the $E / I$ curve, would be sensitive to it, as occurs with differently prepared electrodes.

\section{The cathodic dissolution of the passivating film}

The voltammetric single sweep $E / I$ curves obtained towards the cathodic direction indicate the occurrence of various processes which may contribute to the dissolution of the passivating film. The process of passivity breakdown is however more complex, because once the electrochemical dissolution begins, before the whole material disappears from the electrode surface, mechanical detachment can occur. These results indicate that the material undergoes electrochemical dissolution at the metal/ film interface as already indicated in previous work..$^{5}$ This location of the cathodic reaction facilitates the mechanical separation of the solid deposit from the electrode surface. An important consequence of this phenomenon is that the cathodic charge obtained after integration of the cathodic area is lower than the anodic one, both referred particularly to the current peaks of anodic formation and cathodic dissolution of the insoluble film.

The results show that the cathodic dissolution, if the potential sweep covers only a potential range at the positive side of the rest potential, proceeds mainly by a reaction involving one electron per SCN group, the over-all reaction being expressed by reaction $\mathrm{I}$. This conclusion is drawn from the fact that no additional anodic current peaks are observed during the second potential sweep initiated in the anodic direction.

The situation is different however if the potential sweep extends towards potentials more negative than the rest potential. Under these circumstances, the dissolution apparently shows a further reduction as indicated by reaction III. Both ions are also formed if the potential related to the discharge of thiocyanate ion is reached, as shown by reaction IV. When any of these reactions occurs, the second anodic half-cycle presents two new current peaks, already assigned to the oxidation of sulphide and cyanide respectively.

Naturally these facts make any straightforward interpretation of the cathodic processes, particularly from the kinetic standpoint, difficult at present. Nevertheless, as for the case of the anodic film formation, the electrochemical dissolution according to reaction III should be considered as a quite irreversible process. This is reflected, for instance, in the dependence of the potential related to the maximum cathodic current on the potential-sweep rate: the slope of the corresponding straight line is practically equal to $R T / F$. The dependence of the maximum cathodic current on the potential-sweep rate is not definitely established, as the electrochemical dissolution provokes an uncontrolled mechanical loss of electrode material.

At any rate a plausible mechanism for reaction III can be advanced to explain the $R T\rangle F$ slope already mentioned. Thus, the following reaction scheme is postulated,

$$
\begin{aligned}
(\mathrm{SCN})_{x}+\mathrm{e} & =(\mathrm{SCN})_{x}(\mathrm{e}) \\
(\mathrm{SCN})_{x}(\mathrm{e}) & =(\mathrm{SCN})_{x-1}+\mathrm{SCN}^{-} .
\end{aligned}
$$

Reaction IIIa comprises the charge-transfer step, which consists in the electron attachment to the film, and step IIIb is the separation of an ion and partial electrochemical dissolution of the film.

This treatment admits two limiting possibilities, namely, either step IIIa or step 
IIIb is rate-controlling. The former should be discarded for the type of $\left(V_{\mathrm{c}}\right)_{\max } v s v$ dependence reported above. The second possibility seems more reasonable and its formal kinetic treatment is analogous to that already referred for the anodic film formation. Thus, if reaction II occurs through step IIIa and IIIb, the latter being rate-determining, the following expression results,

$$
\left(V_{\mathrm{c}}\right)_{\max }=\frac{R T}{F} \ln \frac{k F}{k_{\mathrm{III}} R T}+\frac{R T}{F} \ln v,
$$

where $k$ is given by (1). This equation contains the linear $\left(V_{\mathrm{c}}\right)_{\max } v s \ln v$ relationship found in experiments with a slope equal to $R T / F$. This tentative explanation of the cathodic process is satisfactory for the present, although further information about the reaction is required for its better understanding.

\section{The electrode processes under repetitive potential sweeps}

These results were important for the qualitative description of the processes, the potential range for their occurrence and the possible connexion between anodic and cathodic reactions, but from a quantitative standpoint they are not directly comparable to those already discussed. When repetitive potential sweeps are applied to the electrode there is a continuous change of the $E / I$ diagram until a steady display is achieved after a few tens of cycles, due principally to the continuous change of the electrode surface coverage. Therefore, the initially clean electrode surface no longer persists after the first cycle. Furthermore, at appreciably high potential-sweep rates, the amount of film either formed or dissolved is smaller than that expected for a completely covered surface and consequently, when the steady $E / I$ curve has been reached, the processes which they actually undergo, although they are expressed by the same overall reactions, are related to film thickening instead of film growth and to its partial dissolution, during the anodic and cathodic half-cycles, respectively. For these reasons the $E / I$ curves exhibit current peaks lower than those already reported for single-sweep experiments and the reactions proceed over a wider potential range.

Acknowledgement - The authors thank the Consejo Nacional de Investigaciones Cientificas y Técnicas of Argentina for partial financial support.

\section{REFERENCES}

1. G. MetzGer, Rapport CEA-R-2566, Centre d'Études Nucléaires, Saclay, France (1964).

2. A. Éluard and B. Trémllón, J. electroanal. Chem. 13, 208 (1967).

3. R. E. PANzer and M. J. Schaer, J. electrochem. Soc. 112, 1136 (1965).

4. K. F. Denning and K. E. Johnson, Electrochim. Acta 12, 1391 (1967).

5. A. J. Calandra, M. E. Martins and A. J. Arvia, Electrachim. Acta 16, 2057 (1971).

6. R. N. ADAMs, Electrochemistry at Solid Electrodes. Dekker, New York (1969).

7. G. Paus, A. J. Calandra and A. J. Arvía, An. Soc. Cient. Arg. 192, 35 (1971).

8. D. A. VermiLyeA, Advances in Electrochemistry and Electrochemical Engineering, ed. P. DeLAHAY and C. W. ToBias, Vol. 3, P. 211. Interscience, New York (1963).

9. S. SRINIVASAn and E. GiléADI, Electrochim. Acta 11, 321 (1966). 